\title{
FOOD SUPPLIES IN RELATION TO HUMAN NEEDS PART 3. SIGNS AND SYMPTOMS OF DEFICIENCY DISEASES
}

\author{
Chairman, Professor D. Murray Lyon
}

Professor D. Murray Lyon (Clinical Medicine Department, Royal Infirmary, Edinburgh), in his introductory remarks, emphasized the importance at the present time of the early recognition of deficiency symptoms. In this country little evidence had been found, after three years of war, of gross deficiency disease, although subclinical disturbances might be present. There had been no increase in scurvy and in general hospital practice very few cases of rickets had been noted. There had, however, been an increase in the incidence of tuberculosis. Within recent years the public had become health conscious and had come to correlate health with nutrition. One of the chief difficulties at the present time lay in the fact that no yardstick had been found which would adequately measure the state of nutrition, and until such a measure was found the general practitioner had no simple guide to the recognition of malnutrition.

\section{Symptoms and Signs of Deficiency of the B Group of Vitamins \\ Dr. V. P. Sydenstricker (Rockefeller Foundation, New York)}

Requirements for certain members of the B group of vitamins definitely are dependent on the composition of the diet. It is likely that synergistic reactions further condition the requirements. The use of a diet unduly high in refined carbohydrate and lacking in protective foods probably never results in a solitary avitaminosis since the ensuing metabolic disturbances probably involve three vitamins of the B group, perhaps more. Organic diseases which interfere with the absorption or utilization of one vitamin, similarly are effective against the group.

Factors which determine the elinical patterns of deficiency disease remain unknown. It is possible that similar if not identical phenomena result from deprivation of different substances, perhaps at different levels of depletion. At present it is not possible to relate definitely more than a few symptoms and signs to lack of single vitamins.

Vague malaise, weakness, lassitude, nervous irritability, mild depression, muscle pains, anorexia and consciousness of disturbances of gastrointestinal motility are early symptoms common to all B group deficiencies. They may reflect metabolic disorders at a functional stage. As depletion progresses functional changes may become profound, even irreversible, before gross organic lesions develop. More often, physical signs in fairly definite patterns appear. 
Current concepts of the relation of clinical types of deficiency disease to the various components of the B group are based on therapeutic results with vitamins rather than sound experimental observations. All symptoms and signs resulting from dysfunction or actual degenerative changes of the peripheral nerves and heart are attributed to vitamin $B_{1}$ deficiency. Certain dermatoses and lesions of the mucous membranes and symptoms and signs referable to disturbances of the cerebral cortex and midbrain are thought to depend on depletion of nicotinic acid. Other types of changes in the skin and mucous membranes and a variety of disorders of the visual apparatus respond to treatment with riboflavin. There remains a group of dermatoses and perhaps of ocular disturbances which responds only to treatment with sources of the entire B group.

\section{Calcium and Phosphorus Deficiency and Hypoproteinaemia}

Dr. A. Lyall (Department of Clinical Chemistry, Royal Infirmary,

\section{Calcium and Phosphorus}

Disturbances of calcium and phosphorus metabolism as observed in hospital cases may be divided into four main groups:

(1) Due directly to damage to or destruction of the parathyroid glands, as after some cases of thyroidectomy;

(2) Caused as a secondary result of intestinal diseases and disturbances of absorption, e.g., in the group of coeliac diseases and steatorrhoeas or fatty diarrhoeas;

(3) The result of disturbances in blood chemistry due to chronic renal failure in the child or adolescent;

(4) Due to chronic prolonged deprivation of calcium and phosphorus or increased demands on a minimal intake with or without diminished absorption.

In the present discussion we must confine ourselves mostly to the last group, which can be regarded as largely nutritional and not secondary to pre-existing definable organic disease, with resultant failure of absorption or disturbances of cellular metabolism.

The symptoms and signs of abnormal calcium and phosphorus metabolism are associated either with malformations or deformities of the skeleton or with disturbances of neuro-muscular nerve endings, resulting in cramps or tetany, or with capillary endothelial changes of the pernio type.

The evidences of pathological metabolism of calcium and phosphorus can be sought for in several ways, e.g., from:

(a) Clinical manifestations: latent tetany, osteoporosis;

(b) X-ray manifestations: deformities, pathological fractures;

(c) Blood chemistry: values of serum calcium and phosphorus;

(d) Balance experiments, with demonstration of negative or positive balances.

All of these methods are liable to error in interpretation, especially with minor degrees of disturbance. Purely clinical observations may leave voL. 1,1944$]$ 
the observer in doubt, especially since, for instance, so many other clinical manifestations may simulate tetany. It is difficult in the opinion of most radiologists to be certain about minor degrees of osteoporosis. The blood chemistry at any one point in time may be normal even with markedly deficient intakes of calcium and phosphorus, since the blood chemical pattern is maintained, if possible, at the expense of tissue, and particularly of skeletal, stores. Balance experiments are laborious and time consuming, but provide by far the most reliable demonstration of deficiency.

The earlier groups with defined pathology do not interest us here and are fairly clear cut clinical entities met with in every large hospital.

What evidence have we of malformations and diseases directly due to insufficient absorption of these elements or inadequacy of the elements themselves or of vitamin $\mathrm{D}$ ?

(a) Rickets, undoubtedly, as dealt with by Professor Morris (1944);

(b) Chilblains and allied conditions;

(c) Unsatisfactory dentition;

(d) Re-absorption of bone with pathological fractures, deformity, or greater liability to fracture.

Large numbers of chilblain cases show moderate reduction of the serum calcium to levels of 8 to $9 \mathrm{mg}$. per $100 \mathrm{ml}$. Restoration of normal blood chemistry by increased calcium intake and stimulation of absorption is accompanied by disappearance of the chilblain diathesis. Of dentition I am not qualified to speak and will only say that $I$ have been astonished by the fine character of the teeth in many diabetic children and adolescents.

Bone changes are fairly common. One type is seen in recurrent illnesses, e.g., diabetic coma, where lines of abnormal epiphyseal deposit correspond with each attack. Porosis of the shafts of long bones, e.g., humerus and femur, is frequently found in elderly individuals. This may be partly a senile change, but is undoubtedly aggravated by low mineral intake and probably is an important factor in the frequency of fracture, especially of the neck of the femur, in old age.

Long continued low calcium intake results in severe osteoporosis of bone with crushing or destruction of portions of the skeleton. The radiologists note that the vertebrae usually show the first signs, both of porosis and of crushing. This syndrome of crush porosis of the spine has been frequently observed since Meulengracht drew attention to the condition (Meulengracht and Myer, 1937; Meulengracht, 1938). His cases were occasionally aggravated by continuous use of saline aperients. Meulengracht felt justified in classing his series of cases as nutritional osteomalacia. In an investigation of the diets of same 400 families in Copenhagen the intake of calcium was found to be perilously close to the minimum limit. He maintained that, if this were so, conditions were present for the symptoms of deficiency to appear occasionally and that there was lacking only the complete clinical confirmation of the physiological fact that the diet of the adult population was deficient in calcium and vitamin D. His own series of cases provided the answer. Aggravating factors precipitated the bone lesions in a number of cases and included achlorhydria, pyloric stenosis and continuous use of laxatives. The 
symptoms included pain in the back and loins, kyphosis, loss of stature and secondary osteo-arthrosis.

Several cases of this type of senile and nutritional osteoporosis with deformity have recently been observed in Aberdeen. Mrs. D., aged 66, complained for six months of pain in the lower back. X-ray examination revealed generalized osteoporosis of the spine and collapse of several vertebrae from the 9th thoracic to the lumbar region (Figure 1). No evidence

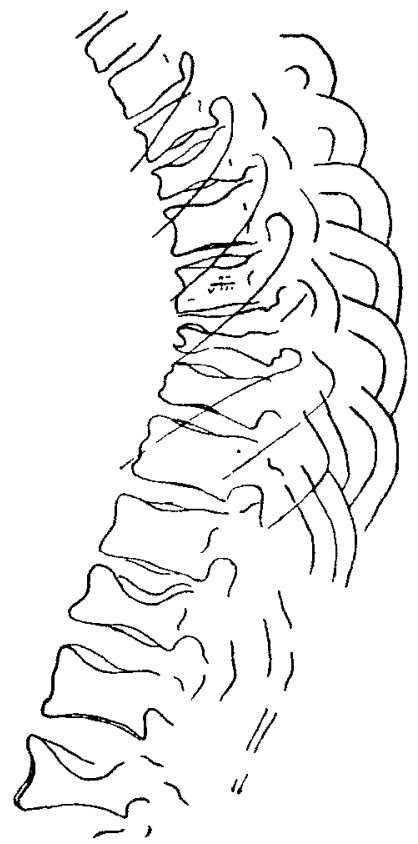

(a)

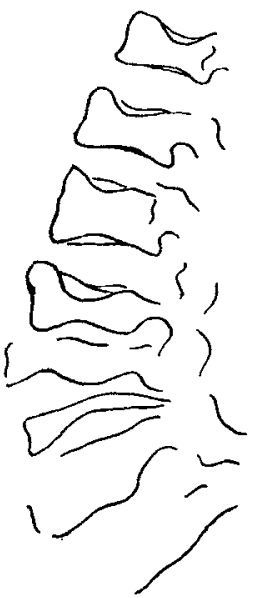

(b)

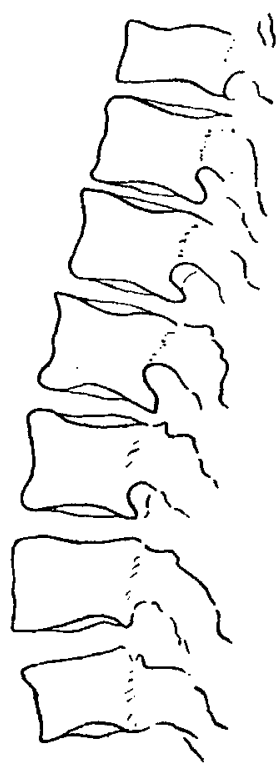

(c)

Figure 1. Nutritional Porosis of Spine.

(a) Thoracic region of spine showing porosis and crushing of 6 th, 8 th, 9 th and 10 th vertebral bodies.

(b) Lumbar region.

(c) Normal lumbar spine.

of any generalized malignant disease of bone or of a primary tumour was discovered. The blood chemistry was normal, showing per $100 \mathrm{ml}$.: plasma protein $5.9 \mathrm{~g}$., plasma phosphatase 16 units, serum phosphorus $2.4 \mathrm{mg}$., serum calcium $10.0 \mathrm{mg}$. It was discovered that although the patient kept hens she did not eat eggs and although she kept cows she did not drink milk. The total daily calcium intake for several years had not exceeded $0.30 \mathrm{~g}$. Urinary calcium excretion was at a very low level and on an experimental hospital diet containing $0.48 \mathrm{~g}$. calcium, the urinary calcium excretion was, on the average, $0 \cdot 12 \mathrm{~g}$.

Although precise information is lacking, some radiologists believe that minor degrees of this type of lesion are much more common than is usually supposed. The work of Owen $(1939,1940)$ has demonstrated quite clearly that the calcium requirement of elderly male subjects approaches voL. 1, 1944] 
that of the earlier decades and that prolonged diminished intake leads to some degree, more or less severe, of generalized osteoporosis. In a series of 10 male patients, whose previous dietetic history was known, balance experiments showed that 5 were in positive and 5 in negative calcium balance on diets containing $520 \mathrm{mg}$. calcium. All showed negative phosphorus balances on this diet with a phosphorus content of $0.8 \mathrm{~g}$. On diets containing $850 \mathrm{mg}$. calcium and $1230 \mathrm{mg}$. phosphorus daily, all achieved positive balance in both elements. In a later series of 7 poorly nourished subjects whose previous diets contained from 225 to $364 \mathrm{mg}$. calcium daily and from 630 to $1400 \mathrm{mg}$. phosphorus daily, it was shown that equilibrium might be established at these low levels but that marked retention of calcium occurred when the intake was raised. Time precluded the possibility of checking skeletal retentions by X-ray observation but, in the initial stages, 4 of the 7 subjects exhibited more or less marked degrees of osteoporosis. It would thus seem that minor degrees of nutritional calcium deficiency may be more common than is supposed. The recognition of this state is difficult unless attention is drawn to the condition by the occurrence of fracture.

\section{Hypoproteinaemia}

The same considerations apply to the incidence of reduction of the blood proteins in hospital observations. Fall in blood proteins is nearly always associated with previous diseases, accompanied by failure of digestion and absorption, impaired synthesis, excessive protein loss or sudden vascular or fluid crises, and the causes can be subdivided as follows:

(a) Renal disease with loss of plasma proteins in urine (20 g. daily);

(b) Impaired synthesis, as in cirrhosis of the liver;

(c) Plasma loss from effusions into scrous sacs, e.g., ascites;

(d) Loss from intestinal fistulac;

(e) Traumatic shock and major surface burns;

(f) Nutritional deficiency alone, or nutritional deficiency complicating the above causes.

The nutritional group includes deficiencies of a minor nature, those occurring in starvation or famine and the conditioned deficiencies of pregnancy and anorexia. Normally the blood proteins range from 6.5 to $8.5 \mathrm{~g}$. per $100 \mathrm{ml}$, with an albumin : globulin ratio of 4.5 to 2.5 . This level is maintained in health when protein intake, digestion, absorption and metabolism, are normal. Considerable periods of diminished protein intake can be experienced without diminution of blood proteins or secondary effects. This is, of course, because body proteins are rapidly mobilized. This phenomenon is seen in any acute fever or condition such as acute pyloric stenosis. After the crisis equilibrium is rapidly re-established. In protein loss, the albumin portion is usually most reduced, with greater resultant osmotic disturbance between intravascular and extravascular fluids. This applies particularly to the hypoproteinaemia of most varieties of renal disease, so that there is an alteration or reversal of the albumin: globulin ratio. Protein replacement and regeneration of blood proteins is very difficult while the renal pathology persists. 
In general, oedema occurs when the total protein content of the blood plasma falls below $5 \mathrm{~g}$. per $100 \mathrm{ml}$. A critical level appears just above $5 \mathrm{~g}$. per $100 \mathrm{ml}$. where the occurrence of obvious oedema is influenced by other factors, principally fluid and chloride balance and possibly endocrine or vitamin effects.

The daily protein intake is important in the avoidance of nutritional types of oedema. The average optimum intake of proteins is probably about $100 \mathrm{~g}$. daily. The minimum possible for short periods without nitrogen loss is about $30 \mathrm{~g}$. daily, provided carbohydrate and fat supplies are adequate. As far as I can calculate, the protein intake under war conditions approximates $60 \mathrm{~g}$. daily, representing roughly a nitrogen exchange of $10 \mathrm{~g}$. This I believe is sufficient for even the adolescent.

Severe nutritional oedema has been frequently described in previous wars and famines. This aspect has recently been fully reviewed by Chen (1942), who studied the nutritional oedema in children in famine areas in China. He made a dietetic study of refugee camps in China, where the diet consisted almost wholly of red beans, soya beans, turmip, rice and wheat flour. Among 903 patients admitted to hospital, 130 children had clinically apparent oedema not due to nephritis or other pathological cause. Wasting of fat and muscles, anaemia and senile wrinkles were present. The hair was dry and brittle, and most showed stomatitis and glossitis; ocular lesions, including xerophthalmia and keratomalacia, were often found. Lesions due to vitamin deficiency were present in many instances and complications with bacterial and parasitic infections were common. Severe anaemia was frequently present. In 26 cases where serum proteins were estimated, 10 showed values below $4 \mathrm{~g}$. per $100 \mathrm{ml}$. and all except 2 had low values. Death resulted in most of the patients with very low serum protein. In 16 patients recovery was associated with increase in blood protein. In a group of 26 children suffering from nutritional deficiency without oedema, 15 showed blood protein values below normal. It thus appeared that factors other than protein deficiency contributed to the ocourrence of oedema.

It is only very rarely that actual hypoproteinaemia without obvious pathological cause is observed. One case of this type was met with recently where recurrent tissue oedema appeared in a female patient aged 20 years. No evidence of nephritis could be discovered and no heart disease was present. The blood chemistry showed, per $100 \mathrm{ml}$.; urea $17 \mathrm{mg}$., plasma $\mathrm{CO}_{2} 59$ vols., plasma chlorides $0 \cdot 61 \mathrm{~g}$., plasma protein $5.41 \mathrm{~g}$., albumin $3 \cdot 22 \mathrm{~g}$., globulin $2 \cdot 19 \mathrm{~g}$., albumin : globulin ratio $1.4: 1$.

Diminution of the chloride intake caused disappearance of oedema and replacement of chloride was followed by recurrence of oedema. A period on high protein diet resulted in increase of the plasma proteins to $6.4 \mathrm{~g}$. per $100 \mathrm{ml}$. and at this level oedema disappeared.

In the view of some workers the oedema of a few cases of toxaemia of pregnancy is the result of chronic deficient protein intake. Thus Arnell and Guerriero (1942) found that among 500 cases of oedema in pregnancy the usual precipitating causes of oedema were cardiac disease, phlebitis or toxaemia. In a survey of 100 pregnant women of the poorer class, the diet was found to be deficient in protein, minerals and vitamins. The mean daily protein intake was $0.78 \mathrm{~g}$. per $\mathrm{kg}$. and in 8 cases with vor. 1, 1944] 
oedema, closely investigated, the blood proteins lay between $3 \cdot 0$ and $5 \cdot 4 \mathrm{~g}$. per $100 \mathrm{ml}$.

The material presented is admittedly rather sketchy and if anything is clear to myself from compiling these notes it is that $(a)$ we have here only a basis for discussion and future work, $(b)$ workers in hospitals perhaps take an exaggerated view of the nutritional abnormalities resulting from disease, and $(c)$ primary nutritional disturbances are rather rare in the material to which we have access.

\section{REFERENCES}

Arnell, R. E. and Guerriero, W. F. (1942). Amer. J. Obstet. Gynec. 43, 467.

Chen, J. (1942). Amer. J. Dis. Child. 63, 552.

Morris, N. (1944). Proc. Nutr. Soc. 1, 148.

Meulengracht, E. (1938). Lancet, 235, 774.

Meulengracht, E. and Myer, A. R. (1937). Acta med. scand. 92, 584.

Owen, E. C. (1939). Biochem. J. 33, 22.

Owen, E. C. (1940). Acta med. scand. 103, 235.

\section{Vitamin D Deficiency}

Professor N. Morris (Department of Materia Medica and Therapeutics, The University, Glasgow)

Although much has been claimed for the use of vitamin $D$ in different diseases, there is no evidence that a deficiency of vitamin $\mathrm{D}$ produces, in the human subject, any disturbance other than that which can be accounted for by defective utilization of calcium and phosphorus. The manifestations depend primarily upon the rate of growth: in infancy and childhood rickets is produced, in adult life, osteomalacia. These two conditions are the same, both being due to defective utilization of calcium and phosphorus.

The classical type of rickets with its marked skeletal deformities has almost disappeared from the industrial areas of this country, but has left in its place a form of the disease which may affect general health to a considerable degree and which is possibly more dangerous because it is not obvious. Formerly the earlier manifestations of rickets were said to occur at about the 5th month, but now it has been shown that, where the mother is suffering from vitamin $D$ and calcium starvation, rickets may appear in the foetus. In the infant and child any of the bony parts may be affected, the localization depending on (1) the relative rates of growth and (2) the stress and strain undergone by the individual regions of the body. The earlier symptoms of rickets are general irritability, some alimentary disturbance, increasing flabbiness, excessive perspiration, especially on the forehead, and a considerable degree of head rolling in consequence of which the hair from the occiput may become scanty. In young infants craniotabes may appear; the older ones usually show some degree of bossing of the skull. The chest is more or less deformed with beading of the ribs and indrawing of the lower thorax and pigeon chest. A well marked spinal curvature may result from softening of the bones and ligaments. Of great importance in the female is distortion of the pelvis, liable as it is to increase the difficulties of childbirth. The limbs are also affected with enlargement of the epiphyses at wrists and ankles and well marked curvatures, especially in femur and tibia. The 
muscles and ligaments are relaxed, so that the child can put his limbs into very abnormal positions, "acrobatic rickets." The abdomen is enlarged, contrasting markedly with the small deformed thorax. Gastrointestinal and respiratory infections are particularly liable to occur and may become very serious. While there is no proof that acidosis is a constant accompaniment of rickets, there is no doubt that acid base equilibrium is particularly unstable in the rachitic infant. Tetany is also a frequent accompaniment. It is usually precipitated by inadequate administration of vitamin $\mathrm{D}$ and indeed is generally associated with signs of very slow early healing.

In the older child the manifestations of rickets are usually limited to deformities of the limbs, especially the legs, and very poor growth. Otherwise the condition is exactly the same as that found in the infant. Coeliac rickets is merely rickets occurring in association with coeliac disease. When this condition is very severe, the skeletal disturbance is confined to a marked degree of osteoporosis associated with a complete cessation of growth. It is only when the growth process is recommenced that the ordinary signs of rickets make their appearance. Renal rickets, although clinically not dissimilar to the late rickets observed in the older child, has probably nothing directly to do with vitamin $\mathrm{D}$ deficiency.

Osteomalacia differs from rickets in the absence of growth in the affected bones. There is a tendency for fractures to occur because of the persistence of some rigid calcified bone. Osteomalacia is most commonly associated with pregnancy and lactation, but Meulengracht (1939) and others have shown that it may be produced apart from these conditions by insufficient intake or absorption (non-tropical sprue) of calcium. While osteomalacia in relation to puerperal conditions chiefly affects the pelvis, the non-puerperal variety often involves the spine alone, with the presenting symptom of pain in the back, sometimes radiating towards the front of the body, and leading to the diagnosis of rheumatism. Often there is stiffness of the limbs, with weakness, especially in the adductor muscles of the thighs. Tetany frequently occurrs.

Although it is true that ordinary clinical examination suffices for the diagnosis of moderate degrees of rickets, most workers would agree that something more is necessary for the detection of milder forms of the disease, when the metabolic disturbances are not sufficiently great or have not continued long enough to produce clinical manifestations. For the diagnosis of milder forms of the disease skiagrams have been used to great advantage both in practice and as an instrument of research, but in the mildest forms of the disease the interpretation of the skiagrams is a matter of considerable difficulty. It is also difficult to estimate, by $\mathrm{X}$-rays alone, the initial stages of healing. Undoubtedly the most accurate method of determining the presence or absence of the rachitic process and its severity is by estimating the actual retention of minerals, but, because this is laborious, time consuming and quite unsuited for routine use, resort has been made to chemical examination of the blood. The serum calcium does not alter markedly in uncomplicated rickets but a reduction of the inorganic phosphorus has long been used as a valuable indication of the presence of rickets. This latter test suffers from some of the defects associated with X-ray examination, in that there is usually little change in the level of serum phosphorus for two to three weeks after voL. 1, 1944] 
the start of therapy, whereas metabolic studies have shown that, within one week, administration of vitamin $D$ leads to a marked increase in mineral retention. Nor is low serum phosphorus pathognomonic of rickets since it may occur in pneumonia and other acute infections, muscular dystrophies and coeliac disease. Further, the onset of tetany causes a marked rise in serum phosphorus although the rachitic state is far from healed. The product of the calcium and phosphorus values of the serum is no more reliable. A product above forty has been taken to indicate healing and one below thirty an active stage. The truth of this statement was disputed by Hess, Lewis and Rivkin (1930) who, on many occasions, obtained products above forty without signs of healing.

Kay (1930) found that in clinical rickets the plasma phosphatase is increased and this has been confirmed by many other workers. Morris, Stevenson, Peden and Small (1937) attempted in a series of 506 infants and children to assess the value of plasma phosphatase as a diagnostic test for rickets and also as a means of determining the presence and rate of healing. In 84.1 per cent. of the cases with clinical or X-ray evidence of rickets the plasma phosphatase was increased above normal limits. It is probable that a rise in plasma phosphatase value is an earlier manifestation of the rachitio state than that provided by ordinary clinical or X-ray examination, but it would be unwise to use the plasma phosphatase value alone as conclusive evidence of the presence or absence of rickets. In the adult it must always be remembered that there are several conditions, such as osteitis deformans and generalized osteitis fibrocystica which lead to high values of plasma phosphatase.

\section{REFERENCES}

Hess, A. F., Lewis, J. M. and Rivkin, H. (1930). J. Amer, med. Ass. 94, 1885. Kay, H. D. (1930). J. biol. Chem. 89, 249.

Morris, N., Stevenson, M. M., Peden, O. D. and Small, J. M. D. (1937). Arch. Dis. Childh. $12,45$.

Meulengracht, E. (1939). Acta med. scand. 101, 138; 157; 187.

\section{The Role of Vitamin A in Nasal Sinusitis in Children}

\section{Mr. J. Gerrie (Royal Hospital for Sick Children, Aberdeen)}

This is an account of investigations carried out at the Rowett Institute and the Sick Children's Hospital, Aberdeen, into the effect of vitamin A in nasal sinusitis.

Although this is one of the commonest of childhood ailments, it is only in the last six years that. paediatricians have become fully aware of the insidious and dangerous part played by infected sinuses. The general public have been brought up to the idea that a child who has a running nose, recurring colds and mouth breathing should have his tonsils and adenoids removed and, if this does not cure him, that he should be left to "grow out of the condition". Unfortunately for the child, the operation seldom helps the sinusitis and, if treatment is not instituted, he reaches adult life with a nasal condition which only radical surgery can help, and even that may be ineffectual. During this time the child, being a carrier, distributes pathogenic organisms to all and sundry. 
Not only is sinusitis common in children, but it is also potentially dangerous and disabling. There are many complications which may have a fatal termination or leave their mark on the individual throughout life. Apart from complications of an acute sinusitis such as orbital cellulitis, meningitis, brain abscess and cavernous sinus thrombosis, there are ear complications, catarrhal and suppurative otitis media, chest complications such as chronic bronchitis, pneumonia, lung abscess and bronohiectasis, and there are many who believe that swallowed material from infected sinuses is a cause of peptic ulcer in the absence of free hydrochloric acid from the stomach. On the other hand, there is so little lymph drainage from the sinuses that they are not likely to be of importance as foci of sepsis.

Sinusitis in children appears to be on the increase. In the month of May, 1939, at the Hospital for Sick Children, Aberdeen, there were 125 cases sent for the removal of tonsils and adenoids and of these 36 , or 29 per cent., had antral infection, the commonest form of sinusitis. In the month of May of this year, there were 148 cases sent and of these 63, or 44 per cent., had infected antra. The methods of diagnosis were the same in the two series, so that there would seem to be some other factor responsible for the somewhat alarming increase.

When a child is first seen with symptoms suggestive of sinusitis, a clinical examination is made and an $\mathbf{X}$-ray photograph taken. This may show that the antra are opaque or have thickened linings. In the diagnosis of sinusitis, two conditions must be excluded; first, the common cold, due to a filter passer, and second, allergic sinusitis, which can be ruled out by the history, including family history, the rcsults of skin tests and examination of the nasal secretion for eosinophiles and $p \mathrm{H}$ value.

Once the diagnosis has been established, treatment is started by weekly antral washings with saline under local anaesthesia. The average number of washings required to clear the antra is three, but as many as twenty may be required and in a small percentage of cases surgery has to be resorted to in an endeavour to clear the nose of sepsis. The results of this method of treatment are not satisfactory. If the children are reexamined from six months to two and a half years later, it will be found that in 60 per cent. the suppuration has recurred. Nor is the cause far to seek, for the antrum may be free of pus and yet have a thickened, infected lining. In view of this state of affairs, it was thought wise to investigate the condition further.

The Pathology. For comparison, samples of tissues from vitamin A deficient rats were examined and the typical lesions of metaplasia and keratinization were obtained in the lining epithelium of the nasal passages. There was little evidence of infection. In addition, sections of antral and ethmoid linings obtained at operation on the human subject were examined and infection was found to be uppermost, metaplasia being observed in a small percentage of cases. This difference can probably be accounted for by the vitamin A intake in the human diet, but experiments are contemplated to determine whether, in the rat with a low but not completely negligible vitamin A intake, infection would take a more prominent place in the picture.

The Clinical Work. The total number of cases of antral suppuration vor. 1,1944$]$ 
examined was 187. All cases of recurring common cold and allergic sinusitis were excluded as detailed above. Of these 187 cases, 88 had pus in both antra and 41 had pus in one antrum, that is, 129 cases were definitely in the suppurative stage of sinusitis. Again, 58 cases were found to be clear on lavage, although they had the typical symptoms of sinusitis and had X-ray evidence of thickened lining in the antra. They were therefore in the pre-suppurative or congestive stage of sinusitis. The commonest infecting organism was the streptococcus, closely followed by the staphylococcus, and less closely by the pneumococcus.

1. The 129 cases in the suppurative stage. Of the 258 antra, pus was found in 217. These cases were divided into two groups: 45 received vitamin $A$ and 84 were used as controls. The 45 cases receiving vitamin $A$ wore given 2 capsules of halibut liver oil, representing 16,000 I.U., daily for a month. In both groups the antra were washed out at weekly intervals till clear. It was found that the average time taken for the antra to clear was almost equal, a fraction over three times in both cases. X-ray photographs were then taken of both groups and it was found that in practically all the thickened lining remained in the sinuses. It was therefore concluded that the increase in vitamin A intake had not influenced the infective process, so far as could be made out at that time.

2 . The 58 cases in the pre-suppurative stage. These were divided for the purposes of the investigation into two groups: 33 were given vitamin $\mathbf{A}$ and 25 were used as controls.

(a) The 33 cases given vitamin $A$. Of these, 25 were given a course of 2 capsules of halibut liver oil daily for a month. The remaining 8 were given vitamin $\mathrm{A}$ by intramuscular injection. The solution used contained 100,000 I.U. per $\mathrm{ml}$; t the dose was $\frac{1}{2}$ to $1 \mathrm{ml}$., the number of injections given depending on the $\mathrm{X}$-ray appearance, an injection being given each week till the mucous membrane flattened out. It was noted in this connexion that if no improvement appeared on the X-ray film, the antrum ultimately passed to the suppurative stage.

(b) The 25 control cases. Apart from preliminary lavage, no treatment was given.

These two groups were subjected to lavage from 1 to 6 months later. For clarity, we had best consider the cases in terms of individual antra: 25 cases or 50 antra were treated for one month with capsules of halibut liver oil, 8 cases or 16 antra had vitamin A by injection and 25 controls or 50 antra had no treatment.

(a) The 50 antra having vitamin $\mathrm{A}$ by mouth. After $\mathrm{I}$ to 6 months 10 antra contained pus; that is, 20 per cent. had gone to the suppurative stage.

The 16 antra treated by injection of vitamin A intramuscularly. After 1 to 6 months, 3 contained pus; that is 19 per cent. had gone to suppuration.

(b) The 50 control antra. After 1 to 6 months, 41 contained pus; that is, 82 per cent. had gone to the suppurative stage.

The $X$-ray findings coincided with the lavage findings. If the antrum was clear, the X-ray was clear or almost so, but if there was pus present, the lining would still be thickened or the antrum opaque. 


\section{Vitamin A Deficiency in Relation to the Health of the Eyes \\ Dr. J. R. Mutch (6 Albyn Terrace, Aberdeen)}

When it was decided early in 1937 that the Rowett Institute would conduct a dietary and clinical survey to study the effect of diet upon health, the vitamin A requirements of healthy individuals of any age were unknown, and there was no clinical or laboratory test which could give any indication as to what was the minimum amount of vitamin $A$ required to support perfect functioning.

It has been known for hundreds of years that night blindness was associated with dietary deficiency, and that the night blindness could be quickly cured by consuming liver or liver oil in sufficient quantities. When it became known that the chief active principle in cod liver oil was vitamin $A$ it was assumed that night blindness was due to vitamin $A$ deficiency. To ascertain whether this assumption could be used as a basis for a test for vitamin A requirements, the study of dark adaptation was undertaken by a team of workers at the Rowett Institute early in 1937. The difficulties encountered and overcome and the conclusions arrived at were detailed in three separate publications, the last being published in December, 1939, two months after the outbreak of war (Mutch and Griffith, 1937; Thomson, Griffith, Mutch and Lubbock, $1939,1,2)$.

For the benefit of the non-medical members of the audience a brief explanation of what is meant by dark adaptation and the principles involved might be of benefit. Dark adaptation is the power that the eye possesses of adapting itself to see at low illuminations. The eye has really three main functions: the perception of light, the perception of form, and the perception of colour. The perception of light is the most primitive of the three and is the last to disappear in a case of progressive blindness. The form sense and the light sense are said to be two entirely different things, but one cannot perceive an object unless it is sufficiently illuminated, so the light sense and the form sense are very closely linked. The amount of illumination required to allow a person to walk about safely after dark is comparatively great compared with what is required to stimulate the light sense at or near the visual threshold.

According to Lythgoe (1926) the illumination of full moonlight is $1 / 100 \mathrm{ft}$. candle. One $\mathrm{ft}$. candle is the amount of light falling on a surface that is illuminated by a standard candle placed at $1 \mathrm{ft}$. distance; $1 / 100 \mathrm{ft}$. candle is the amount of illumination on the screen when the candle is $10 \mathrm{ft}$. distant, the illumination being inversely proportional to the square of the distance of the light from the screen. The illumination near the visual threshold is the amount of illumination on the screen if the candle is placed $1000 \mathrm{ft}$. from the screen. The average time taken by normal subjects to become adapted to an illumination equal to $1 / 500$ of the illumination of full moonlight is under 5 minutes, so that if a person sits in the dark for 5 minutes before stepping outside into the black out the vision should be sufficiently adapted to allow of safe progress. As the process is a unilateral one the closing or covering of one eye for 5 minutes is sufficient.

After a suitable intrument had been found and a technique elaborated voL. 1, 1944] 
which eliminated several factors that intcrfered with the accuracy of the test, work was started upon picked groups of schoolchildren and adults; 323 schoolchildren and 53 adults werc examined. Although we were working with an instrument that was capable of registering at an illumination lower than what Ly thgoe (1926) cstimated the visual threshold for normal subjects to be, we were able to find only 2 adults and 1 child who did not reach this threshold if given sufficient time to do so. This meant that if the visual threshold was really influenced by the intake of vitamin $A$, no vitamin A deficiency was present amongst the general population of the north east of Scotland, or that the vitamin A requirement for the proper functioning of dark adaptation was less than the vitamin A required for other purposes.

As the time taken to reach the final visual threshold varied greatly in different individuals it was thought that the rate of adaptation might be used as a test. It was found that the time taken by certain individuals to become completely adapted could be definitely shortened by increasing the intake of vitamin A. Unfortunately for the value of the test, however, it was found that the time taken to reach the final visual threshold was influenced by factors other than the intake of vitamin A.

After examining subjects of both sexes, all ages, and different social standings, some who were known to be taking a defective diet and some who were given supplements of vitamin $\mathrm{A}$ far in excess of what could possibly be regarded as a normal daily intake, it was concluded that: (1) there was a relationship between vitamin $A$ intake and dark adaptation, and (2) the dark adaptation test was unreliable for the estimation of dietary vitamin A deficiency.

This work was completed in the summer of 1939 , and since then much work has been done upon the same problem by investigators all over the world, but mostly in America. Many of the published results have been very conflicting, showing that the subject is not straightforward, but recent studies have given full support to the Rowett team's conclusions (e.g., Feldman, 1939; Steffens, Bair and Sheard, 1939; Kellett, 1940; MeDonald and Adler, 1940).

Since the war the conditions have been ideal for detecting any clinical abnormality in dark adaptation, but in my school, hospital, and private practice, apart from cases of retinitis pigmentosa of which there are about 100 in the north east of Scotland, I have come across only two patients who complained of night blindness; both were males and both were neurasthenic. When tested, both showed a raised visual threshold, but showed other signs of functional disorder such as twitching of the eyelids and variation in visual acuity upon repeated examination. Defective adaptation in neurasthenia has been noted by other investigators (Wittkower, Rodger, Scott and Semeonoff, 1941). The defect of adaptation is due partly to want of concentration, but there is also an actual raising of the visual threshold since an increased stimulus seems to be required before the sensation reaches consciousness. Many soldiers who complained of night blindness in former wars undoubtedly fell into this catcgory and were not suffering from vitamin $A$ deficiency.

As to other clinical evidence of vitamin A deficiency among the general population of the north east of Scotland during the war period I would like to give my own experience. I come across two types of cases among 
my school and hospital subjects. The first is that of babies, about a year to 15 months old, who are not thriving, are pale and have severe photophobia. This class of case is due in most instances to lack of knowledge on the mother's part when the child has been weaned. The treatment is to take the child into hospital, give it a nourishing diet suitable for its age, cod liver oil by mouth and general irradiation with ultraviolet light. In a month to 6 weeks the child is cured, but if the mother has not received some elementary dietetio instructions from the district nurse while the child is in hospitel, a relapse is common.

In older children we get chronic blepharo-conjunctivitis and corneal ulceration. The majority of these children are undernourished, on diets with too much carbohydrate and too little protein and fat. These children, I have not the slightest doubt, are deficient in vitamin A, but no one will convince me that this is the only deficiency from which they are suffering. To give concentrated vitamin A treatment to these children is wrong. The rational treatment is to see that they receive a well balanced diet, supplemented with certain things that we know are rich in the vitamins suspected to be lacking. The vitamins are to be given, not as pure synthetic drugs, but as foods, rich in vitamins, but combined with other natural substances present in the foods, about the value of which we probably know nothing. To give a concentrated vitamin to a semi-starved patient might cause definite harm. Large doses of pure vitamin A have been given to normal subjects without, it is said, causing any harm, but it is a different thing to give excessive doses to an undernourished individual.

Before the war chronic blepharitis was very common, but curiously enough during the war it has been less evident. This is due to several factors. Dietetics is recognized by everyone as being of major importance. Rationing, even to the most ignorant, emphasizes the value of certain foods. A great many artificial foods are unobtainable, so that people are being forced, even against their will, to eat the best kind of food in the best proportions. Furthermore working class families, especially in country districts, are earning more money, and are thus in a position to buy better food.

The provision of free and cheap milk to children at school, along with a hot midday meal, is undoubtedly a factor in the improvement and maintenance of health.

I have, I think, indicated that the problem of detecting vitamin A deficiency has many pitfalls, but all the work done in this field up to date, indicates that there is no marked vitamin A deficiency amongst the general population of the north east of Scotland.

REFERENCES

Feldman, J. B. (1939). Arch. Ophthal., N.Y., 22, 595.

Kellett, C. E. (1940). J. Hyg., Camb., 40, 439.

Lythgoe, J. R. (1926). Spec. Rep. Ser. med. Res. Coun., Lond., no. 104.

McDonald, R. and Adler, F. H. (1940). Avch. Ophthal., N.Y., 24, 447.

Mutch, J. R. and Griffith, H. D. (1937). Brit. med. J. ii, 565.

Steffens, L. F., Bair, H. L. and Sheard, C. (1939). Proc. Mayo Clin. 14, 698.

Thomson, A. M., Griffith, H. D., Mutch, J. R., Lubbock, D. M. (with Owen, E. C. and Logaras, G.) (1939, 1). Brit. J. Ophthal. 23, 461.

Thomson, A. M., Griffith, H. D., Mutch, J. R., Lubbock, D. M. (with Owen, E. C. and Logaras, G.) (1939, 2). Brit. J. Ophthal. 23, 697.

Wittkower, E., Rodger, T, F., Scott, G. I, and Semeonoff, B. (1941). Brit, med. J. ii, $571 ; 607$.

voL. 1,1944$]$ 


\title{
Vitamin Deficiency in the Pathogenesis of Disease: Diagnostic Criteria
}

\author{
Dr. J. Yudkin (Dunn Nutritional Laboratory, Cambridge)
}

The diagnosis of deficiency disease may be considered from two aspects. First, is a certain recognized disease, of hitherto unknown aetiology, due in reality to vitamin deficiency? Second, are certain obscure signs and symptoms in an individual due to vitamin deficiency? Examples of the first are claims that vitamin deficiency plays a part in the production of renal lithiasis (Higgins, 1935), disseminated sclerosis (Mellanby, 1934) and certain muscular dystrophies (Bicknell, 1940). This type of problem is perhaps one which the research worker can best solve; the second problem, however, is one which every clinician has at some time or other to face. A patient is seen with an unusual form of keratosis of the skin, or with oedema which does not respond to ordinary therapy, or with a sore tongue with a few other signs or symptoms, or with an unusual type of subcutaneous haemorrhage. To what extent are vitamin $A$, vitamin $B_{1}$, riboflavin and vitamin $C$ respectively implicated in the production of these disturbances in the individual?

We may consider four stages in the diagnosis of deficiency disease:

I. Existence of deficiency

A. General evidence of deficiency

Test 1. Evidence of inadequate diet

Test 2. Evidence of defective absorption

Test 3. Evidence of increased utilization

B. Specific evidence of deficiency

Test 4. Tests for specific deficiency

II. Deficiency as cause of condition

A. Presence of signs expected in the deficiency

Test 5. Signs resembling those in recognized deficiency disease

Test 6. Signs associated with those of recognized deficiency disease

Test 7. Signs resembling those of animals on a.deficient diet

Test 8. Signs resembling those of humans on an experimental diet

B. Cirre of signs by correction of deficiency

Test 9. Therapeutic test

In the first stage, we look for general evidence of deficiency; in the second, for specific evidence; in the third stage, for the presence of signs expected in the deficiency; in the fourth, we attempt to cure the signs by correction of the deficiency. The first two stages are to decide on the existence of a deficiency in the condition; the second two stages are to show whether the deficiency is the cause of the condition.

Altogether there are nine types of test which may be used in diagnosing deficiency disease but, as we shall see, unless more than one criterion is used, the conclusions drawn are apt to be misleading.

(1) Evidence of Inadequate Diet

A dietary history is an essential first step in diagnosis. The following conditions are especially liable to lead to an inadequate diet:

(a) Low income levels. Foods which are good sources of vitamins are 
generally more expensive; cheaper foods supply mainly calories (Orr, 1936).

(b) War. War time measures have decreased the disparity between the diets of different classes. Nevertheless, there are many who still cannot afford to buy the whole of their meat or bacon ration or to spend much on vegetables. On the other hand, since war leads to restricted imports, to a decreased man power for food production and to the destruction of crops and other foodstuffs, it may be a potent cause in the production of deficiency disease.

(c) Season. The level of vitamin C in foods is lower in the spring and early summer, so that the effects of its deficiency are most likely to be seen at this time (Harris, 1942).

(d) Geographical position. Differences in food production and dietary habits lead to the classical examples of geographic endemic deficiency disease such as the association of beriberi with polished rice and pellagra with maize.

(e) Special diets. Possibly the commonest cause of adult scurvy in Britain is the consumption of a too rigid "gastric" diet by patients with peptic ulcer, without adequate precautions for assuring the supply of vitamin C (Harris, Abbasy and Yudkin, 1936). Also, beriberi has been reported in food cranks who have lived on a diet containing excessive amounts of highly purified carbohydrates.

(f) Institutions. Outbreaks of deficiency disease are often reported from institutions. In prisons and asylums, this may be due to inadequate allowance for food. But apart from economic considerations, ignorance or lack of care may be responsible for a diet of poor quality. For example it requires a special technique to preserve vitamin $\mathrm{C}$ in large scale cooking (Macrae, 1942).

(2) Evidence of Defective Absorption

(a) Water soluble vitamins. Many affections of the gastro-intestinal tract decrease the absorption of vitamins of the B group. Hyperemesis gravidarum (Strauss and McDonald, 1933) and alcoholic gastritis (Minot, Strauss and $\mathrm{Cobb}, 1933$ ) are often associated with deficiency of vitamin $\mathrm{B}_{1}$; in the latter there is probably also a diminished intake of the vitamin. Gastrectomy, colitis and intestinal obstruction frequently lead to a complex deficiency of vitamins of the B group (see Editorial in the British Medical Journal, 1942 i, 77).

(b) Fat soluble vitamins. The absorption of these substances is bound up with that of fat. Thus, in obstructive jaundice, there is diminished absorption of vitamin A (Breese and McCoord, 1940) and of vitamin $K$ (Warner, Brinkhouse and Smith, 1938, 1, 2), and large doses of liquid paraffin lead to decreased absorption of carotene (Rowntree, 1931).

(3) Evidence of Increased Utilization

(a) Pregnant and lactating women. In some degree pregnancy and lactation increase the demand for all the nutrients including the vitamins. Osteomalacia and beriberi are examples of deficiency diseases which may be precipitated by pregnancy.

(b) Heavy manual workers. The utilization of many nutritional factors is increased with increased physical exertion. Many Europeans voL. 1, 1944] 
consume diets which probably contain no more vitamin $B_{1}$ than those consumed by many Chinese; the high incidence of beriberi among the latter is probably associated with the very heavy work which they do.

(c) Fever. There is apparently an increased destruction of vitamin $\mathrm{C}$ and possibly other vitamins during fever (Abbasy, Harris and Ellman, 1937; Harris, Passmore and Pagel, 1937). Usually the primary condition overshadows deficiency of the vitamin but this deficiency may well play a part in delaying recovery.

(4) Tests for Specific Deficiency

(a) Vitamin concentration in the blood. The determination of the blood concentration of vitamins $A, B_{1}$ or $C$ has often been used to assess the nutritional level in respect of these factors. The results of such in: vestigations, however, appear to depend to a large extent on the immediate past diet. A very short time on a diet high in vitamin $A$, for example, will lead to high blood levels although the subject still shows signs of deficiency (Yudkin, 1941); the converse is also true. Estimations of vitamin $\mathrm{C}$ in whole blood or plasma have been found to be less reliable than estimations in the white cell layer (Heinemann, 1938).

(b) Vitamin excretion in the urine. With the water soluble vitamins, measurement of the amount excreted in the urine and especially of the rapidity with which large doses are excreted have been useful for detecting slight deficiency of vitamin $C$ (Harris and Ray, 1935), vitamin $B_{1}$ (Harris and Leong, 1936; Wang and Yudkin, 1940), and nicotinic acid (Kodicek and Wang, 1941).

(c) Functional tests. Impaired dark adaptation, increased capillary fragility or a rise in blood phosphatase have been used to demonstrate mild deficiency of vitamins $A, C$ and $D$. A rise in pyruvic acid in the blood or urine after the ingestion of glucose has been suggested as a means of recognizing early deficiency of vitamin $B_{1}$ (Banerji and Harris, 1939). It must be borne in mind, however, that tests such as those of dark adaptation and capillary fragility, although superficially they appear very simple to employ, require most careful application and rigid control (Hecht and Schlaer, 1938; Editorial, 1942).

\section{(5) Signs Resembling those in Recognized Deficiency Disease}

The realization that the neuritis of alcoholism and that of pregnancy toxaemia were due to deficiency of vitamin $B_{1}$ came, partly at any rate, from the recognition of the similarity between these and the signs of mild "dry" beriberi. But this type of evidence must be used carefully: it has led, for example, to the quite illogical use of vitamin $B_{1}$ in neuritis of many sorts, including sciatica (Roch and Sciclounoff, 1938).

(6) Signs Associated with those of Recognized Deficiency Disease

(a) In individuals. In individuals with signs of a deficiency disease, the presence of other signs whose pathogenesis is obscure suggests that these are also due to the same deficiency. Thus, obscure neurological signs found in Cingalese prisoners appeared to be due to deficiency of vitamin A since other stgns of $A$ deficiency, e.g., phrynoderma, were also present (Nicholls, 1935). Since, however, multiple deficiency is common, caution must be used in interpreting such findings. Some of the changes in the skin and tongue in pellagra were thought to be due to the lack of the pellagra preventing factor; when the latter was isolated as nicotinic acid 
it was found that they were due to a superimposed deficiency of riboflavin (Young, 1927-28; Sydenstricker, 1941). Incidentally, this type of evidence can be used in the opposite way; for example, it was at one time suggested that disseminated sclerosis and subacute combined degeneration of the cord were due to deficiency of vitamin A, but the fact that other signs of this deficiency are rarely found in these conditions makes this unlikely.

(b) In a population. If a deficiency disease is common in a certain population, the same deficiency may often be the cause of other less well defined conditions. Much of the so called toxaemia of pregnancy in Hong Kong where beriberi is common, has been shown to be due to deficiency of vitamin $B_{1}$ (Nixon, 1944).

(7) Signs Resembling those of Animals on a Deficient Diet

Analogy with animal experiments has proved very useful in recognition of signs of human deficiency. The production of haemorrhage due to lack of vitamin K (Dam and Schönheyder, 1934) and vascularization of the cornea due to lack of riboflavin (Bessey and Wolbach, 1939; Wolbach, 1937), are examples of this. On the other hand, such analogy must not be carried too far, as has been done with vitamin $\mathrm{E}$ and the production of neuromuscular disease (Bicknell, 1940) or vitamin A and the production of neurological disease.

(8) Signs Resembling those of Humans on an Experimental Diet

As might be expected, there are many difficulties in conducting such experiments on anything like an adequate number of subjects; moreover, the conclusions reached are frequently conflicting. Thus some workers have claimed that a dietary deficiency of vitamin A produces a deterioration in dark adaptation within a few days (Hecht and Mandelbaum, 1940), whilst others have found no change after 5 or 6 months (Steffens, Bair and Sheard, 1939). It is possible that these divergent results are due to such factors as differences in individual requirement, differences in the stores of the vitamin before the experiment is begun, and the existence of other deficiencies in the diet.

\section{(9) Therapeutic Test}

Wherever possible, the effect of correction of the supposed deficiency should be observed. However, many reports in the literature of the cure of symptoms and signs by the administration of a vitamin are vitiated by the use of inadequate controls and especially the failure to allow for spontaneous remission. On the other hand, even if deficiency really exists, negative results may follow the administration of the missing factor. Often this is due to inadequate dosing or to defective absorption, sometimes to the fact that the pathological process has progressed too far. It is not always possible, for example, completely to cure long standing peripheral neuritis of beriberi by the administration of vitamin $\mathrm{B}_{1}$.

Again, the possibility of the simultaneous existence of other deficiencies must be borne in mind. It is often overlooked that a diet is frequently deficient in several factors, that the administration of only one of these may produce no improvement and that this does not imply that the diet must necessarily have been adequate in this factor. For example, Peterhead children on diets undoubtedly deficient in vitamins $A$ and $D$ voL. 1,1944$]$ 
as well as many other nutrients were no better than the controls when given these two substances (Sutherland, 1934). It was accepted in this experiment that deficiency of one or more other nutrients was the limiting factor in preventing improvement. It is probable that the lack of effect of supplements of vitamin $\mathrm{C}$ in the oft quoted experiment with South African miners (Fox, Dangerfield, Gottlich and Jokl, 1940) was due to the similar existence of multiple deficiency.

When a positive effect is obtained by the exhibition of a vitamin supplement, it is not always legitimate to assume that this has proved the existence of a deficiency. The fact that vitamin $\mathrm{C}$ is diuretic and hence relieves the oedema of cardiac failure (Evans, 1938) does not of course imply that the condition is due to deficiency of the vitamin. Again, if, as has been suggested, large doses of vitamin D have a favourable effect on psoriasis (Brunsting, 1938) it is not to be inferred that psoriasis is a deficiency disease. It is important, in other words, to distinguish between replacement therapy and pharmacological therapy.

General Comments. We may conclude by a consideration of one or two general principles which must be borne in mind.

(a) Multiple deficiency. Human dietaries are such that deficiency of one nutrient only is unlikely to occur. This means that tests 1 to 4 may indicate deficiency of a nutritive factor which is not the cause of the condition under investigation. The signs which will occur in a multiple deficiency will depend partly on the relative extent of the various deficiencies and partly on the capacity of the organism to store the different dietary factors.

(b) Individual variation in requirement. It cannot be expected that all individuals have exactly the same requirements of the various nutritional components. It is possible that there are also racial as well as individual differences. It is stated that Rumanian and Russian prisoners in a German camp during the lasst war were receiving the same diet, which produced pellagra in the former and scurvy in the latter (Bigwood, 1944).

(c) Other constituents of the diet. It has been shown that signs of deficiency of riboflavin can be considerably aggravated if the deficient subjects are dosed with other components of the vitamin B complex (Sebrell and Butler, 1939; Sydenstricker, Sebrell, Cleckley and Kruse, 1940), and there is similar experimental evidence in dogs (Morgan, 1941). This provides another reason for considering the whole of the diet in attempting the diagnosis of deficiency disease.

(d) Specificity of tests for deficiency. No single test can be held to prove deficiency. There are, for example, other causes of poor dark adaptation than deficiency of vitamin $A$. It is possible also to have a high level of vitamin $A$ in the blood co-existing with definite functional deficiency of this vitamin (Yudkin, 1941).

Finally, it should be stressed that, even if deficiency has been proved, it may be the effect rather than the cause of the condition. An extreme example is deficiency of vitamin $\mathrm{C}$ in tuberculosis, in which it is clear that no one would suppose that the deficiency causes the infection. On the other hand, it should be remembered that, even when it is not the ultimate cause of a definite pathological state, deficiency may be a predisposing cause. It is likely, for example, that deficiency of either vitamin $\mathrm{C}$ or 
nicotinic acid renders the individual more readily susceptible to ulcerative stomatitis.

\section{ReferenCES}

Abbasy, M. A., Harris, L. J. and Ellman, P. (1937). Lancet, 233, 181.

Abbasy, M. A., Hill, N. G. and Harris, L. J. (1936). Lancet, 231, 1413.

Banerji, G. G. and Harris, L. J. (1939). Biochem. J. 33, 1346.

Bessey, O. A. and Wolbach, S. B. (1939). J. exp. Med. 69, 1.

Bicknell, F. (1940). Lancet, 238, 10.

Bigwood, E. J. (1944). Proc. Nutr. Soc. 1, 16

Breese, B. B. and McCoord, A. B. (1940). J. Pediat. 16, 139.

Brunsting, L. A. (1938). Proc. Mayo Clin. 13, 280.

Dam, H. and Schönheyder, F. (1934). Biochem. J. 28, 1355.

Editorial (1942). Lancet, 243, 699.

Evans, W. (1938). Lancet, 234, 308.

Fox, F. W., Dangerfield, L. F., Gottlich, S. F. and Jokl, E. (1940). Brit. med. J. ii, 143.

Harris, L. J. (1942). Lancet, 242, 642.

Harris, L. J., Abbasy, M. A. and Yudkin, J. (1936). Lancet, 230, 1488.

Harris, L. J. and Leong, P. C. (1936). Lancet, 230, 886.

Harris, L. J., Passmore, R. and Pagel, W. (1937). Lancet, 233, 183.

Harris, L. J. and Ray, S. (1935). Lancet, 228, 71.

Hecht, S. and Mandelbaum, J. (1940). Amer. J. Physiol. 130, 651.

Hecht, S. and Schlaer, S. (1938). J. opt. Soc. Amer. 28, 269.

Heinemann, M. (1938). J. clin. Invest. 17, 751.

Heinemann, M. (1941). J. clin. Invest. 20, 39.

Higgins, C. C. (1935). J. Amer. med. Ass. 104, 1296.

Kodicek, E. and Wang, Y. L. (1941). Nature, Lond., 148, 23.

Macrae, T. F. (1942). Lancet, 242, 207.

Mellanby, E. (1934). Nutrition and Disease. Edinburgh: Oliver and Boyd.

Minot, G. R., Strauss, M. B. and Cobb, S. (1933). New Engl. J. Med. 208, 1244.

Morgan, A. F. (1941). Science, 93, 261 .

Nicholls, L. (1935). Indian med. Gaz. 70, 550.

Nixon, W. C. W. (1944). Proc. Nutr. Soc. 1, 13.

Orr, J. B. (1936). Food, Health and Income. London: Macmillan.

Roch, M. and Sciclounoff, F. (1938). Schweiz. med. Wschr. 50, 1343.

Rowntree, J. I. (1931). J. Nutvit. 3, 345.

Sebrell, W. H. and Butler, R. E. (1939). Publ. Hlth Rep., Wash., 54, 790.

Steffens, L. F., Bair, H. L. and Sheard, C. (1939). Proc. Mayo Clin. 14, 698.

Strauss, M. B. and McDonald, W. J. (1933). J. Amer. med. Ass. 100, 1320.

Sutherland, R. (1934). Brit. med. J. i, 791.

Sydenstricker, V. P. (1941). Ann. intern. Med. 14, 1499.

Sydenstricker, V. P., Sebrell, W. H., Cleckley, H. M. and Kruse, H. D. (1940). J. Amer. med. Ass. 114, 2437.

Wang, Y. L. and Yudkin, J. (1940). Biochem, J. 34, 343.

Warner, E. D., Brinkhouse, K. M. and Smith, H. P. (1938, 1). Amer. J. med. Sci. 196, 50 .

Warner, E. D., Brinkhouse, K. M. and Smith, H. P. (1938, 2). Proc. Soc. exp. Biol., N.Y., 37, 628.

Wolbach, S. B. (1937). J. Amer. med. Ass. 108, 7.

Young, T. C. M. (1927-28). Indian J. med. Res, 15, 455.

Yudkin, S. (1941). Lancet, 241, 787.

\section{Nutritional Iron Deficiency Anaemia in War Time}

\section{Professor L. S. P. Davidson (Department of Medicine, University of Edinburgh)}

As we enter the fourth year of the war, with its increased mental and physical strain and inevitable dietary restrictions, the assessment of the health of the nation becomes an urgent necessity. Nutritional deficiencies voI. 1,1944$]$ 
in a population can be assessed in various ways, the estimation of iron deficiency being one method. The advantage of this method is that iron deficiency can be accurately determined by estimation of haemoglobin concentrations. If such an investigation is made on representative samples of the population in war time the results can then be compared with similar figures obtained in peace time, and in this way the effect of war conditions on national health can be demonstrated.

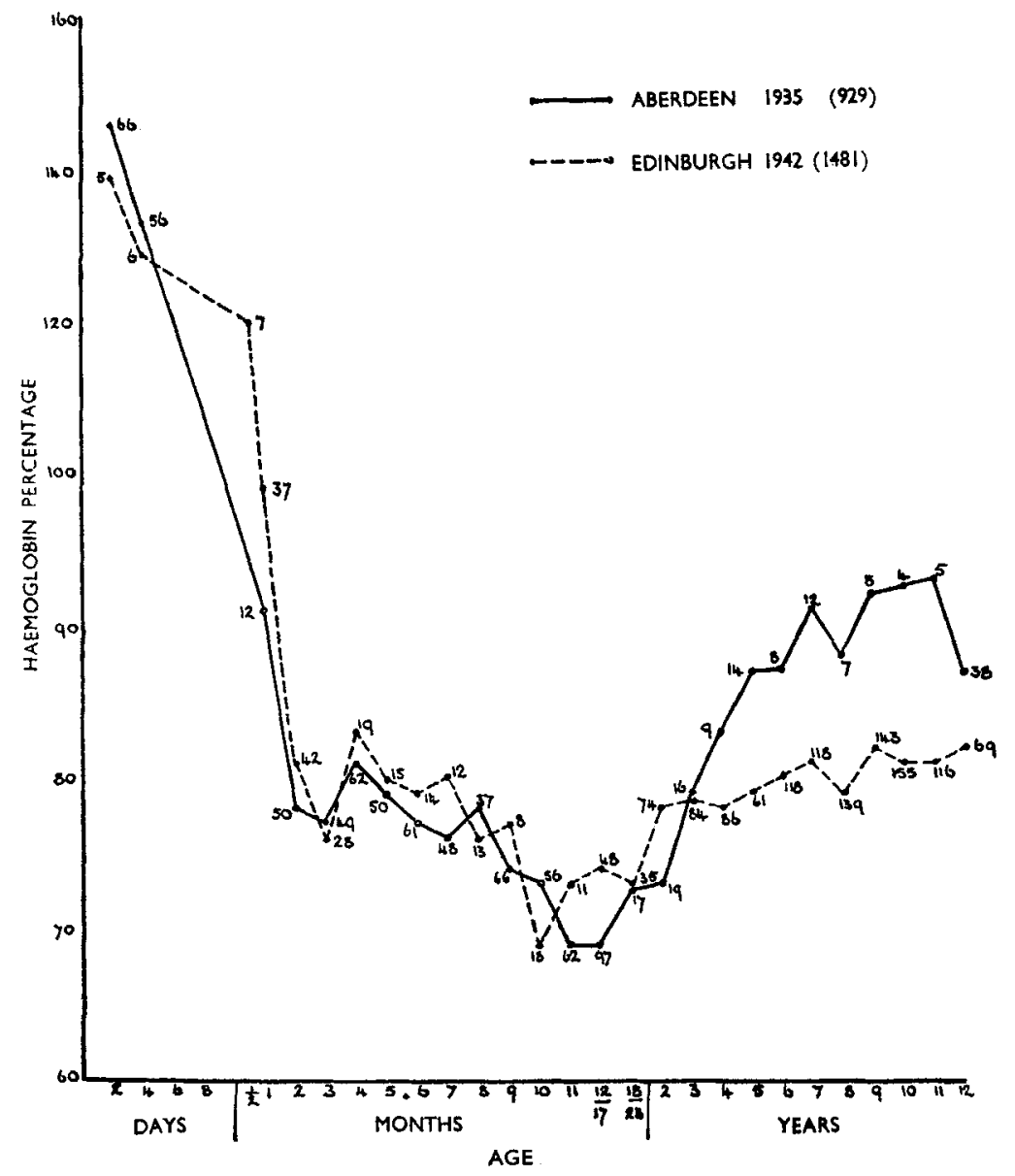

Figure 1. Haemoglobin Levels in Infants and Children.

This communication describes an investigation into the incidence of nutritional iron deficiency anaemia in infants, preschool children, schoolchildren and pregnant women in Edinburgh in 1942. The results are shown in Tables 1 to 6 and in Figures 1 and 2.

Infants and Preschool Children. The haemoglobin levels of 562 infants and preschool children (birth to 4 years) are shown according to age in Table 1. Table 2 gives the haemoglobin ranges found in 263 Edinburgh 
FOOD SUPPLIES IN RELATION TO HUMAN NEEDS. 3 children between 2 and 23 months. It also compares these ranges in 120 Edinburgh infants (9 to 23 months) with 298 infants of the same age groups examined in Aberdeen in 1935. The following conclusions can be drawn from a study of these tables and Figure 1.

The incidence of anaemia in infants in Edinburgh is still high, since 83 per cent. were found to have a haemoglobin level less than the widely accepted figure of $86 \pm 5$ per cent. as suggested by Mackay (1933).

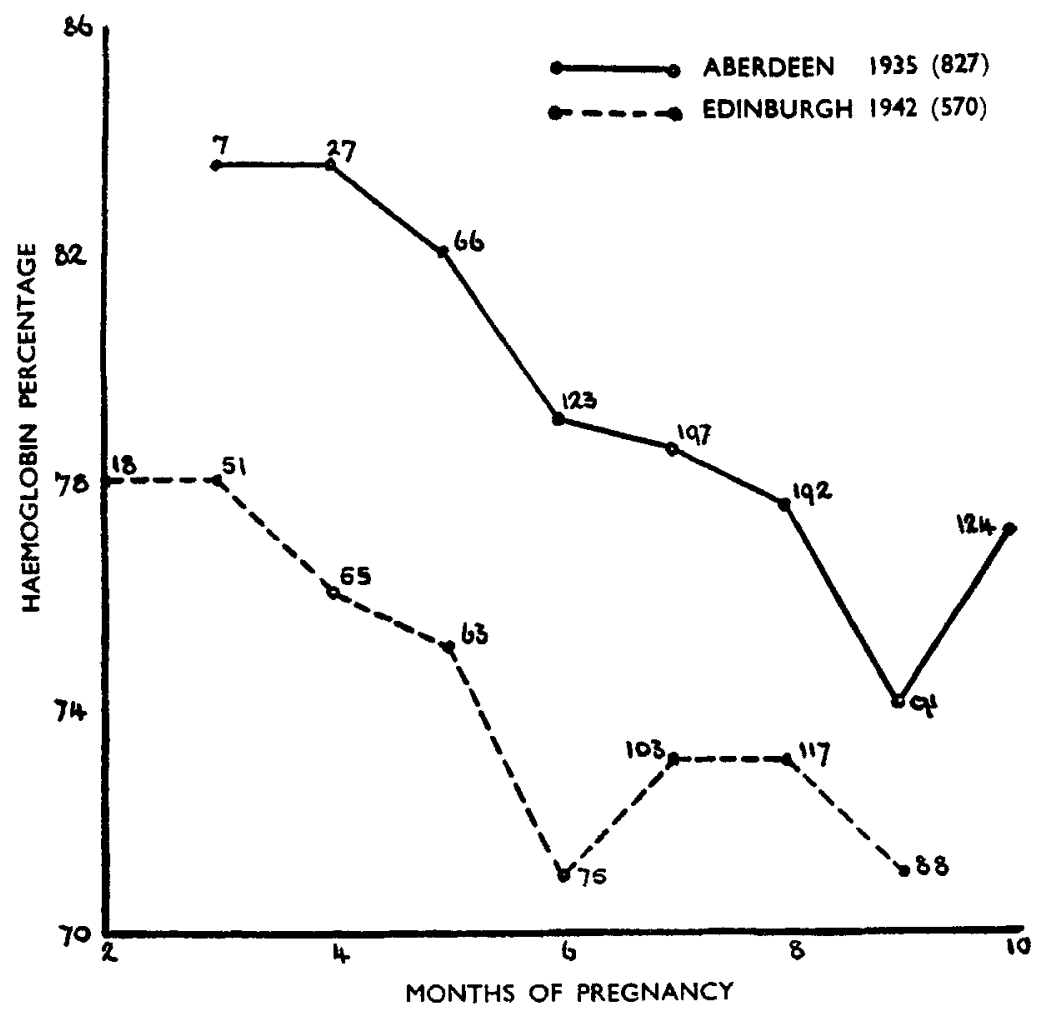

Figure 2. Haemoglobin Levels of Pregnant Women According to Months of Pregnancy.

The incidence of anaemia is, however, slightly less in Edinburgh in 1942 than in Aberdeen in 1935, particularly in the group showing severe anaemia.

A study of Table 1 and Figure 1 indicates a steadily rising haemoglobin level up to the age of 3 years in the Edinburgh series and thereafter the rise flattens out up to the school age of 5 years, in contrast with the Aberdeen series where the rise continues steeply.

Schoolchildren 5 to 12 Years. In Table 3 are shown the haemoglobin levels according to age of 917 schoolchildren examined in Edinburgh in 1942 in 4 council day schools.

In Table 4 the haemoglobin levels are grouped in ranges and in Table 5 voL. 1,1944$]$ 
the incidence of anaemia in schoolchildren in Edinburgh in 1942, is compared with the incidence in a similar age group in Aberdeen in 1935.

The following conclusions may be drawn from a study of these tables and Figure 1:

Whereas anaemia in the Aberdeen schoolchildren was practically absent in $\mathbf{1 9 3 5}$ it was present in approximately 50 per cent. of Edinburgh schoolchildren in 1942. If the normal figure for healthy schoolchildren is $95 \pm 5$ per cent., then 92 per cent. of Edinburgh children in 1942 had a subnormal haemoglobin level. It will be noted that the number of Aberdeen schoolchildren examined was only 67 . At the time it was considered unnecessary to examine further individuals of this age group because of the low incidence of anaemia discovered in children belonging to the poorest class of the community whose parents were mostly unemployed.

Pregnant Women. The haemoglobin levels of 570 Edinburgh women are shown in Table 6 grouped according to haemoglobin ranges and in Figure 2 according to months of pregnancy. Comparable figures for 819 pregnant women examined in Aberdeen in 1935 are shown in both the table and graph.

It is generally accepted that a physiological dilution of the blood occurs during pregnancy, which steadily increases up to full term. It must be taken into account when estimating the degree of anaemia by haemoglobin levels and a correction accordingly made. The correction suggested is 5, 10 and 15 per cent. for the first, second and third trimesters, respectively, or if a large group of women is examined, with the stage of pregnancy equally scattered throughout the three trimesters, an allowance of 10 per cent. should be made.

Since the lower figure for normality for a non-pregnant woman is 90 per cent., a haemoglobin level of 80 per cent. has been selected as the lower limit of normality for pregnant women equally scattered through the three trimesters of pregnancy.

On this basis it will be seen that 82 per cent. of the Edinburgh series had a subnormal haemoglobin level as compared with 49.5 per cent. in the 1935 Aberdeen series.

A study of Figure 2 shows a close parallelism between the two series except that at all months the haemoglobin levels of the Edinburgh series are approximately 7 per cent. lower than those of the Aberdeen series. It should be noted also that the degree of anaemia at the commencement of pregnancy is greater in the Edinburgh women than in the Aberdeen women.

Summary. 1. Iron deficiency anaemia was extremely common in 1942 in infants, schoolchildren and pregnant women in Edinburgh.

2. The effects of war time dietary and other war time conditions increased the incidence of anaemia in pregnant women and caused the development of anaemia in schoolchildren, a class apparently little affected by iron deficiency prior to 1939 .

3. Measures for the prevention and correction of nutritional iron deficiency anaemia in the various classes discussed are urgently required. Such measures must consist either in the administration of medicinal iron or in improvement of the diet with particular reference to foodstuffs known to be rich in iron or by a combination of both methods. 

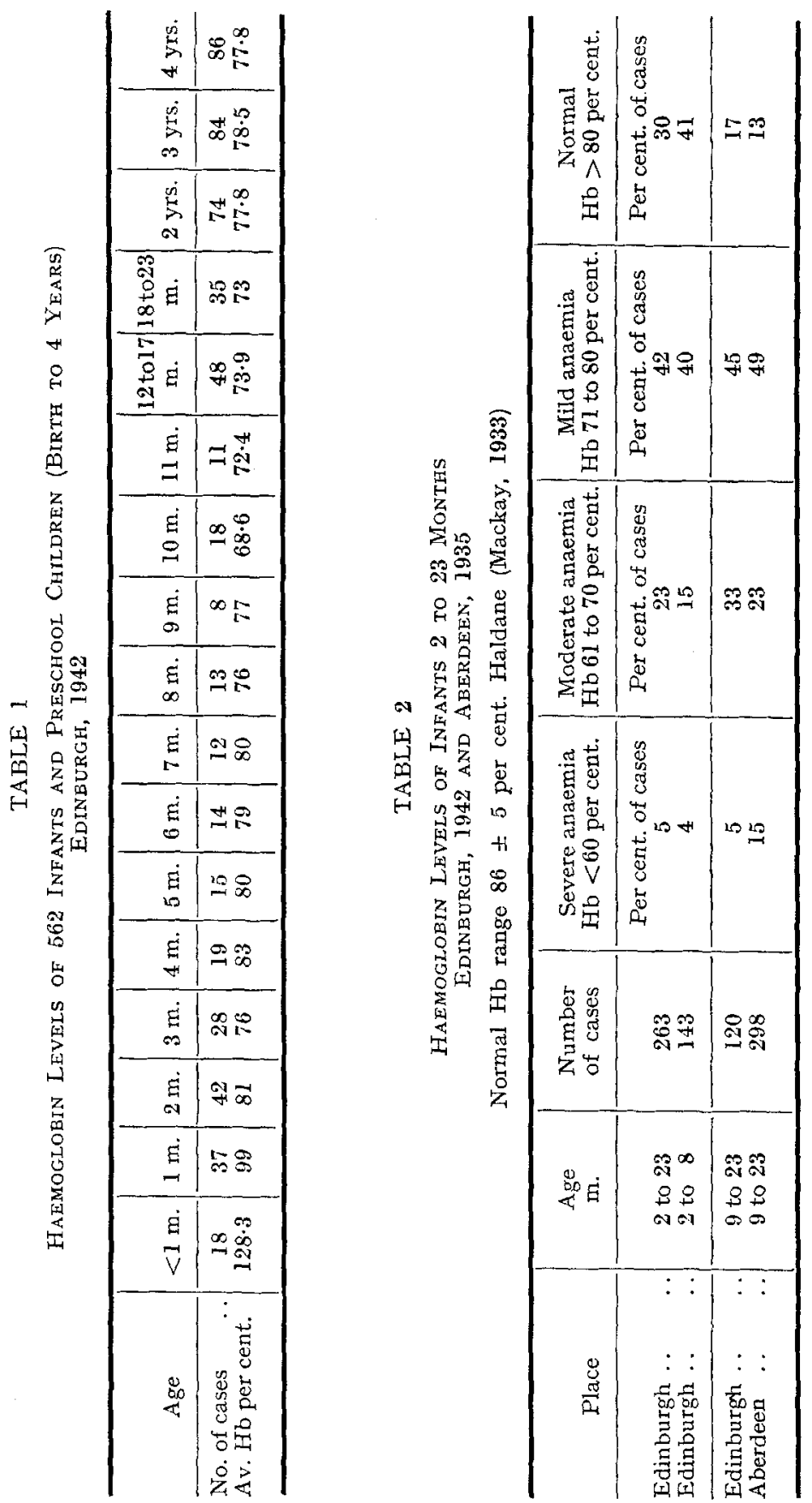

vor. 1,1944$]$ 


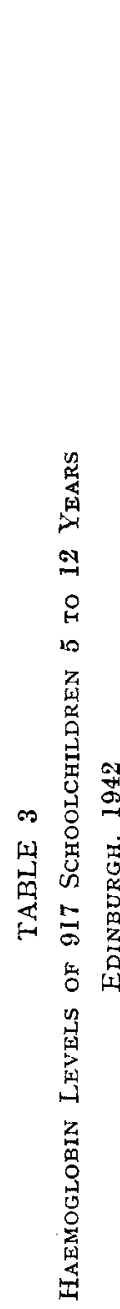

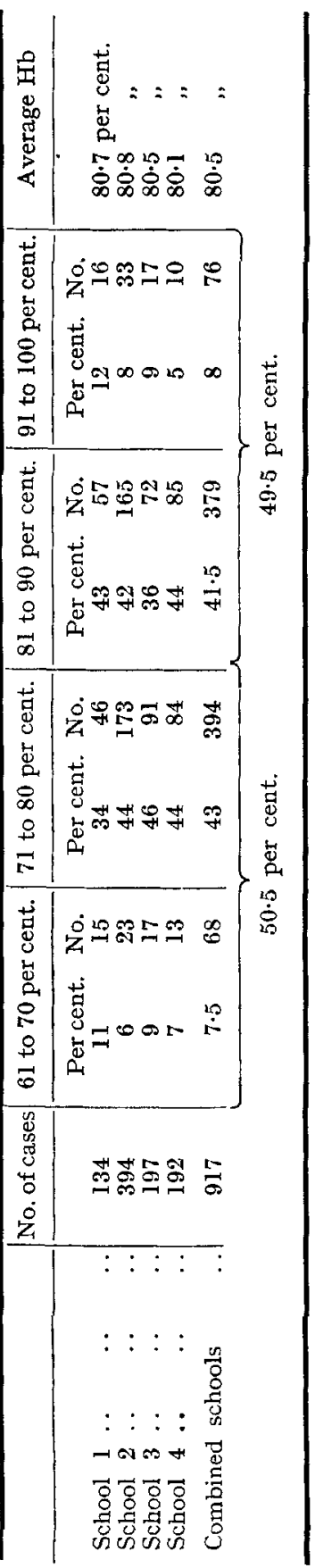


FOOD SUPPLIES IN RELATION TO HUMAN NEEDS. 3167

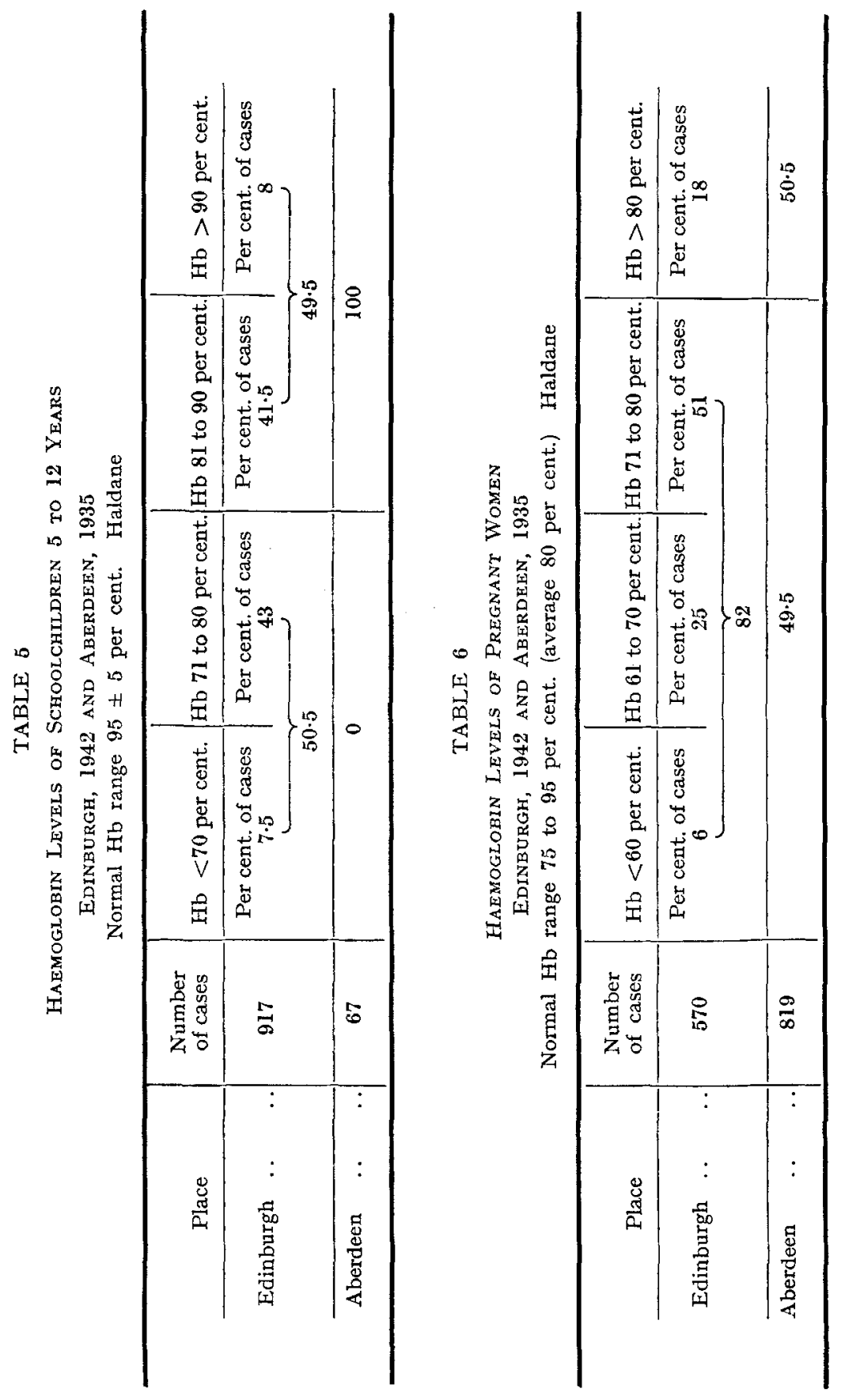

vor. 1,1944$]$ 
REFERENCES

Davidson, L. S. P., Donaldson, G. M. M., Lindsay, S. T. and McSorley, J. G. (1943). Brit. med. J. ii, 95.

Mackay, H. M. M. (1933). Arch. Dis. Childh. 8, 221.

\section{NOTE ADDED IN PROOF}

The investigation into iron deficiency anaemia in war time has been considerably extended (Davidson, Donaldson, Lindsay and McSorley, 1943) since the above communication was made, and a correction factor for the pipette, dilution tube and colour tube of the Haldane haemoglobinometer used has been supplied by the National Physical Laboratory. The correction factor varies with the haemoglobin readings, e.g., between the range 53 to 87 per cent. our instrument was giving a reading approximately 2 per cent. too low. When this correction factor is applied to the figures given above, the data obtained provide no reason for materially altering the conclusions reached in regard to infants and preschool children, namely, that the Edinburgh series, 1942, shows an improvement over the Aderdeen series, 1935. When the correction factor is applied for schoolchildren 5 to 12 years of age, it still does not alter the general conclusion that the incidence of anaemia in schoolchildren in Edinburgh in 1942 is much higher than in Aberdeen in 1935. The number of schoolchildren, however, in 1942 with a haemoglobin level of 80 per cent. or less is reduced from 50 to $39 \cdot 3$ per cent. Similarly in regard to pregnant women, the above conclusions still hold good, but the Edinburgh 1942 figures should be raised by approximately 2 per cent.

Recent unpublished investigations carried out in Edinburgh eighteen months after the original investigations described above indicate a progressive and significant increase in the haemoglobin levels of schoolchildren and pregnant women which the author attributes to the increased iron, vitamin $B$ and protein intake resulting from the introduction of the national loaf.

\section{Diet Deficiencies in Animals}

\section{Professor H. Dryerre (Royal (Dick) Veterinary College, Edinburgh)}

It might be assumed that farm animals living largely on natural and unprocessed foodstuffs would be immune from the diseases about which we have heard today, but this is not so. Domesticated animals, in contradistinction to human beings, are intensively inbred in order to promote more rapid growth, greater weight and increased production. Their food may come entirely from grazing, or may be supplemented by harvested crops such as turnips, hay, dried grass and concentrates; or the animals may be entirely stall fed.

Prolein. If animals do not get a sufficiency of proteins they cease to thrive, and this condition becomes a major economic problem in areas widespread over the world. A protein intake of only 4 per cent. of the food not only gave stunted growth in cattle, but resulted in the stoppage of oestrus, or its recurrence at long irregular intervals, and infertile matings (Hart, Guilbert and Goss, 1932).

The quality of the proteins is also of importance. Litters from pregnant sows given proteins of vegetable origin only, showed a high death rate which was reduced by 75 per cent. when meat scraps were added to the ration (Doyle, 1942).

A condition which has been a concern to veterinarians for generations is hysteria in dogs. It seems particularly to affect animals fed on dog biscuits. Recently it has been shown that it is due to the absence of lysine from the diet (Frederick and Robinson, 1941). This amino-acid is not heat stable and is destroyed in the preparation of the biscuits. The addition of lysine to the diet cures the hysteria. 
Carbohydrates. A disease which causes great economic loss in this country and in America is acetonaemia in milch cows. It is usually found in stall fed animals and seems to be intimately bound up with the carbohydrate supply. It generally occurs shortly after calving, and renders the milk unusable because of its high acetone content. The cow is usually a heavy milker, and the owner, in trying to maintain production, increases the protein content of the diet at the expense of the carbohydrates. There results a deficiency of blood glucose for the energy requirements of the animal, with a consequent increase in fat metabolism accompanied by an increase in the concentration of ketone bodies in the blood. The liver glycogen is depleted. The most effective cure is the intravenous administration of glucose and the giving of molasses orally. Today such treatment is difficult and thousands of gallons of milk are lost.

Minerals. Throughout the world millions of pounds have been lost annually as a result of deficiency of minerals in the diets of animals. This is due partly to natural deficiencies in the soil, and partly to the depletion of the mineral content of the soil by the raising of successive generations of animals which are ultimately transported to the food markets of the world, taking with them in their skeletal tissues the valuable calcium and phosphorus. This is becoming a serious problem on the mountain sheep grazings in Scotland where the reinforcement of the soil by chemical manuring is both impracticable and uneconomical.

Of all the elements necessary for the growth and development of animals none is more important than phosphorus. This is seen particularly in cattle. A deficiency results in swollen and painful joints in the fore limbs; in consequence the hind legs are brought forward under the body in order to support the weight, and the back becomes arched. The animals, if range fed, ultimately die of starvation, as they are unable to forage for food.

A consideration of the phosphorus requirement cannot be dissociated from the calcium requirement. These elements are present in the diets in varying proportions. It is generally conceded, however, that provided there is present a sufficiency of both, the actual ratio is less important.

There are many milch cows at the height of lactation living in a condition of negative calcium balance, drawing upon their skeletal reserves, and this should be borne in mind. In a large dairy, stall fed cows were given a ration of soya bean, shelled yellow maize and straw. They steadily deteriorated and milk yield. fell to half the expected amount (Hastings, 1942). This was attributed to the high $\mathrm{P}: \mathrm{Ca}$ ratio in the soya bean together with a low total calcium intake. The condition was remedied by the addition of limestone to the diet.

Iron and Trace Elements. In widely scattered areas a condition of "wasting" in animals has been reported, usually in cattle and sheep which are dependent on grazing alone. The names given to the syndrome are as varied as the districts in which it is found. In Scotland it is commonly known as "pine." The animals are unthrifty, having staring coats, become emaciated and die. It is prevented or cured by the administration of iron preparations, or by changing the grazing for a period of a few weeks, preferably twice a year. Such a condition reported in the island of Tiree was causing financial losses ruinous to many of the islanders. In collaboration with the Rowett Institute we carried through voL. 1,1944$]$ 
an investigation on the island, and found that the pining could be prevented or cured by the administration of crude iron oxide (Greig, Dryerre, Godden, Crichton and Ogg, 1933).

Evidence is now available which suggests that the condition, at least in some areas, is due primarily to a deficiency not of iron but of cobalt or copper. In Australia and New Zealand, where pining yielded to crude iron oxide therapy, analysis of the iron preparation used showed that the beneficial results were due entirely to traces of cobalt present. The administration of chemically pure salts of cobalt gave the same result (Underwood and Filmer, 1935). For sheep, as little as $0.2 \mathrm{mg}$. cobalt daily changed a steady loss in weight to a gain of $2 \mathrm{lb}$. per week. On the northern slopes of the Cheviots and in eastern Rosshire similar results have been obtained (Stewart, unpublished data). Treatment for three weeks per year is sufficient to cure or prevent the disease.

From Australia also there has been reported a condition in cattle in which they suddenly fall dead in the field (Bennetts and Hall, 1939). In one district alone there were over 1000 deaths in five years. Most of these deaths were of animals 4 to 7 years old; there were no losses in cattle under 15 months. It was demonstrated that these animals suffered from a chronic deficiency of copper, and the condition could be arrested by the administration of $40 \mathrm{mg}$. of this element daily. It is interesting to note that this chronic deficiency caused myocardiac fibrosis and degeneration of the kidney glomeruli. The sudden death was attributed to cardiac failure.

Deficiency of copper is thought to be a predisposing factor in a disease found in sheep in north Derbyshire called "swayback" (Dunlop and Wells, 1938). Over 100 farms are affected, comprising an area of 25,000 acres. The lambs shortly after birth become ataxic and are unable to raise themselves to suckle. On some farms 50 per cent. are affected. The death rate is about 100 per cent. In Table 1 are given the results of a field experiment demonstrating the efficacy of copper therapy in its prevention (Dunlop and Wells, 1938).

TABLE 1

Copper Defictency and the Incidence of Swayback in Lambs

\begin{tabular}{|c|c|c|c|c|c|}
\hline \multirow{2}{*}{$\begin{array}{l}\text { Minerals fed } \\
\text { (10 mg. per day) }\end{array}$} & \multirow{2}{*}{$\begin{array}{l}\text { Total } \\
\text { ewes }\end{array}$} & \multirow{2}{*}{$\underset{\text { born }}{\operatorname{Lambs}}$} & \multicolumn{2}{|c|}{$\begin{array}{c}\text { Swayback } \\
\text { No. of cases }\end{array}$} & \multirow{2}{*}{$\begin{array}{l}\text { Lambs affected } \\
\text { per cent. }\end{array}$} \\
\hline & & & Expected & Actual & \\
\hline $\begin{array}{c}\mathrm{Co}, \mathrm{Cu}, \mathrm{Mn}, \mathrm{B} \\
\mathrm{Co} \\
\mathrm{Cu} \\
\mathrm{Mn} \\
\text { None }\end{array}$ & $\begin{array}{l}307 \\
272 \\
388 \\
300 \\
539\end{array}$ & $\begin{array}{l}355 \\
365 \\
513 \\
423 \\
741\end{array}$ & $\begin{array}{l}40 \\
24 \\
35 \\
44 \\
-\end{array}$ & $\begin{array}{r}7 \\
38 \\
9 \\
66 \\
113\end{array}$ & $\begin{array}{c}1 \cdot 97 \\
10 \cdot 3 \\
1 \cdot 75 \\
15 \cdot 6 \\
15 \cdot 2\end{array}$ \\
\hline
\end{tabular}

(Dunlop and Wells, 1938, modified).

Deficiency of manganese in the diet of poultry produces a bone disease called perosis, wherein the leg bones are distorted, giving rise to a slipping of the metatarsal tendons. The bone lesions may be prevented by as little as 3.0 p.p.m. of manganese in the rations (Schaible and Bandemer, 1942). Even if sufficient manganese be present, an unbalanced diet 
containing excess calcium or phosphorus will still produce the condition by rendering the manganese unavailable.

Vitamins. Domesticated animals are not immune from a deficiency of vitamins in their diet. Deficiency diseases are more commonly met in artificially fed stock, but even grazing animals may show symptoms.

Vitamin A. All farm animals need vitamin A. Deficiency may arise from a variety of causes. Sunbaked pastures lose their carotene by drying and bleaching. Stored hay and maize may lose 60 per cent. in seven months, 75 per cent. in a year. Vitamin A deficiency produces a variety of lesions, xeroph thalmia, nyctalopia, papilloedema, even permanent blindness due to constriction of the optic nerve, diarrhoea, sterility, acute laminitis, and demyelination of the central and peripheral nerves.

In one farm in North America with 250 head of cattle, in spite of storage of vitamin A from earlier grazing, 100 died of vitamin A deficiency in the winter because of the poor roughage supplied (Hart and Guilbert, 1933). In a herd of 200 milch cows fed on brewer's grains, beans, bran and wheat straw, of the 150 calves born, 80 per cent. were blind.

Young animals depend for their supply of vitamin A on the maternal milk, since they cannot utilize carotene. This is of special significance in Guernsey and Jersey cows, which very incompletely convert carotene into vitamin A. Calves receiving an insufficiency of this vitamin develop white scour and not infrequently pneumonia. This condition is very prevalent in Scotland, and the death rate is high.

Vitamin A deficiency in pigs very seldom gives rise to eye lesions. More commonly one finds inco-ordination of the hind limbs, jerky progression and inability to rise. There is no interference with appetite and growth. Typical symptoms were seen in pigs on a presumably sufficient diet of maize, tankage, linseed meal, dried skim milk, liver, alfalfa and minerals. The pigs had been on this diet for three years before symptoms developed. Cod liver oil and fresh alfalfa gave only incomplete recovery. Post mortem examination showed demyelination of the cord and spinal nerves.

Vitamin A deficiency in the horse very seldom causes xerophthalmia, but that it affects equine epithelial structures has been strikingly demonstrated by its effect upon the hoof. Some years ago the horses in the Finnish army received as their standard daily ration $10 \mathrm{lb}$. oats, $11 \mathrm{lb}$. hay and $5 \frac{1}{2} \mathrm{lb}$. straw. About 25 per cent. of the animals were affected. The hoofs were dry, brittle and furrowed, and showed a tendency to crumble. The condition did not clear up when vitamin $\mathbf{D}$ was given, but was cured by grazing or by giving silage or cod liver oil (Klemola, 1933).

In poultry, deficiency of vitamin A causes nutritional roup. The nictitating membrane becomes shiny, and there are poultaceous discharges at the eyelids. Ulcers appear in the mouth and oesophagus. Birds are easily frightened and exhibit inco-ordination of the legs. The condition is commonly seen at the end of a long dry season. Over 80 per cent. of the flock may be affected. The mortality rate is high.

Vitamin $D$. Pigs and poultry suffer more than any of the roughage eating animals from deficiency of this vitamin. Typical rickets is the result. In several pig feeding farms in the Midlands I saw whole litters vos. 1, 1944] 
with bent legs and swollen joints, and exhibiting dirty staring coats. About half of them were given 500 I.U. of vitamin D daily. When seen three months later they were in the pink of condition. Most of the untreated piglets had had to be slaughtered.

Many cases of vitamin D deficiency are found in calves born in the winter months to stall fed cows receiving poor hay, particularly if the calf gets access to concentrates. The back is arched, the coat is staring and there is general unthriftiness. A lowering of the blood phosphorus content is the earliest sign. The condition can be prevented by the daily intake of 3 to $4 \mathrm{lb}$. of sun cured hay, by administration of cod liver oil, by ultraviolet light or by sunlight (Rupel, Bohstedt and Hart, 1933). Table 2 gives the essential data of an experiment designed to show the benefits of these methods of treatment.

TABLE 2

Effect of Vitamin D Supplement on Calves Receiving a Rachitogenic DIET FOR 34 WEEKS

\begin{tabular}{|c|c|c|c|c|}
\hline & $\begin{array}{l}\text { Group I } \\
\text { basal diet } \\
\text { alone }\end{array}$ & $\begin{array}{c}\text { Group II } \\
\text { basal diet } \\
\text { plus } \\
\text { oxidized } \\
\text { cod liver oil } \\
30 \mathrm{ml} .\end{array}$ & $\begin{array}{l}\text { Group III } \\
\text { basal diet } \\
\text { plus ultra- } \\
\text { violet light } \\
\text { radiation } \\
30 \text { mins. }\end{array}$ & $\begin{array}{l}\text { Group IV } \\
\text { basal diet } \\
\text { plus } \\
\text { sunlight } \\
6 \text { to } 7 \text { hrs. }\end{array}$ \\
\hline $\begin{array}{l}\text { Av. age at start, days } \\
\text { Av. weight at start, lb. } \\
\text { Av. weight at end, lb. } \\
\text { Av. ration, daily, lb. }\end{array}$ & $\begin{array}{l}17 \cdot 0 \\
122 \cdot 4 \\
387 \cdot 6 \\
9 \cdot 53\end{array}$ & $\begin{array}{l}15 \cdot 5 \\
121 \cdot 8 \\
606 \cdot 8 \\
11 \cdot 33\end{array}$ & $\begin{array}{c}16 \cdot 2 \\
115 \cdot 0 \\
543 \cdot 0 \\
10 \cdot 69\end{array}$ & $\begin{array}{c}16 \cdot 8 \\
116 \cdot 2 \\
485 \cdot 0 \\
9 \cdot 57\end{array}$ \\
\hline
\end{tabular}

Blood; serum Ca and plasma $\mathrm{P}$ (mg. per $100 \mathrm{ml}$.)

\begin{tabular}{l|rc|cc|cc|cc} 
& $\mathrm{Ca}$ & $\mathrm{P}$ & $\mathrm{Ca}$ & $\mathrm{P}$ & $\mathrm{Ca}$ & $\mathrm{P}$ & $\mathrm{Ca}$ & $\mathrm{P}$ \\
Beginning of experiment & $10 \cdot 5$ & $\mathbf{7 \cdot 6 8}$ & $10 \cdot 5$ & $9 \cdot 28$ & $\mathbf{1 0 \cdot 3}$ & $\mathbf{9} \cdot \mathbf{1 3}$ & $10 \cdot 8$ & $7 \cdot 72$ \\
End of experiment & $\mathbf{9 \cdot 5}$ & $\mathbf{3} \cdot 60$ & 11.0 & $\mathbf{8 \cdot 2 9}$ & $\mathbf{1 2 \cdot 0}$ & $\mathbf{8 \cdot 2 7}$ & $\mathbf{1 1 \cdot 6}$ & $\mathbf{7 \cdot 3 4}$ \\
\hline
\end{tabular}

(Rupel, Bohstedt and Hart, 1933, modified).

Vitamin $B$ Complex. Ruminants do not require this in their diet as they are apparently able to synthesize the various components. Effects of deficiency are, however, seen in poultry, pigs, dogs, foxes and lions.

Riboflavin is necessary to prevent chickens developing "turned in toe" paralysis, as a result of which they are ultimately unable to stand. This is found especially in fowls kept under hygienic conditions, on wire floors. Average diets contain $100 \mu \mathrm{g}$. riboflavin per $100 \mathrm{~g}$., but chickens require a minimum of $250 \mu \mathrm{g}$. to prevent this paralysis (Bethke and Record, 1942). Riboflavin is also essential for efficient utilization of the feed. Data are given in Table 3, showing the effects of graded amounts of riboflavin on the incidence of paralysis and on food economy.

In a large piggery a group of animals showed loss of weight, inappetence, dermatitis of ears and body, with watery diarrhoea (Madison, Miller and Keith, 1939). The animals were given $50 \mathrm{mg}$. nicotinic acid daily. There was an unmistakable improvement in 12 days, and complete recovery in 6 weeks.

On the other hand nicotinic acid had no effect in preventing or curing a dermatitis of a pellagra like nature which attacks chicks. In one 
TABLE 3

The Effect of Graded Amounts of Riboflavin on Growth, Curted Toe Paralysis and Feed Utilization of Chicks

\begin{tabular}{c|c|c|c|c|c|c|c}
\hline $\begin{array}{c}\text { Riboflavin } \\
\text { additions } \\
\text { to } 100 \mathrm{~g} . \\
\text { ration }\end{array}$ & $\begin{array}{c}\text { Number } \\
\text { of } \\
\text { trials }\end{array}$ & $\begin{array}{c}\text { Number } \\
\text { of } \\
\text { chicks }\end{array}$ & $\begin{array}{c}\text { Average } \\
\text { weight } \\
\text { at eight } \\
\text { weeks } \\
\text { g. }\end{array}$ & $\begin{array}{c}\text { Chicks } \\
\text { showing } \\
\text { paralysis } \\
\text { per cent. }\end{array}$ & $\begin{array}{c}\text { Affected } \\
\text { chicks } \\
\text { recovered } \\
\text { per cent. }\end{array}$ & $\begin{array}{c}\text { Mortality } \\
\text { per cent. }\end{array}$ & $\begin{array}{c}\text { Feed } \\
\text { per } \\
\text { gain } \\
\text { g. }\end{array}$ \\
\hline 0 & 8 & 192 & 168 & 66 & 9 & $9 \cdot 4$ & $5 \cdot 31$ \\
50 & 6 & 142 & 270 & 65 & 25 & $8 \cdot 4$ & $3 \cdot 50$ \\
75 & 5 & 122 & 342 & 57 & 48 & $1 \cdot 6$ & $3 \cdot 20$ \\
100 & 7 & 167 & 391 & 28 & 67 & $6 \cdot 0$ & $3 \cdot 00$ \\
150 & 8 & 192 & 452 & 14 & 100 & $2 \cdot 6$ & $2 \cdot 84$ \\
200 & 8 & 217 & 456 & 7 & 100 & $3 \cdot 7$ & $2 \cdot 82$ \\
300 & 4 & 134 & 461 & 0 & - & $3 \cdot 7$ & $2 \cdot 80$ \\
\hline
\end{tabular}

(Bethke and Record, 1942).

poultry farm of over 2000 birds, 200 developed the symptoms, feathers dirty, rough and staring, eyelid margins granular and adherent, skin of feet discoloured and split (Doyle, 1942). The. birds were on a mixed diet, and the trouble was attributed to deficiency of pantothenic acid. Addition of this to the diet cured the dermatitis immediately. Chicks require about $600 \mu \mathrm{g}$. per $100 \mathrm{~g}$. food.

In a silver fox farm containing over 900 breeding vixens it was noticed (personal observations) that some of the cubs showed loss of power in their rear limbs, and were limping round in circles, and many had their heads retracted to one side (Chastek paralysis). A vitamin B complex deficiency was suspected and the cubs were immediately given marmite. Within 6 hours an improvement set in and on the third day the foxes appeared normal. These cubs received a large proportion of fresh fish in their diets, and an explanation of the above syndrome has recently been given by American workers (Green, Evans, Carlson and Swale, 1942), who encountered the same condition. It appears that raw fish viscera, heads, fins and tails have the power of inactivating vitamin $B_{1}$, producing a condition comparable with alcoholic encephalopathy in man. This inactivation is quantitative, and is prevented by cooking the fish.

Some years ago I was asked to examine two lion cubs about 3 months old, which were obviously in ill health. The animals were very docile and could be handled with ease. The rear limbs in particular had lost their power and were supersensitive to touch. A vitamin $B_{1}$ deficiency was suspected and they were given marmite daily. Three weeks later the animals had fully recovered. The change was spectacular; they were vicious and so full of vitality that it required two men to hold each of them.

\section{REFERENCES}

Bennetts, H. W. and Hall, H. T. B. (1939). Aust. vet. J. 15, 152.

Bethke, R. M. and Record, P. R. (1942). Poult. Sci. 21, 147.

Doyle, L. P. (1942). J. Amer. vet. med. Ass. 100, 208.

Dunlop, G. and Wells, H. E. (1938). Vet. Rec. 50, 1175.

Frederick, L. D. and Robinson, H. E. (1941). J. Amer. vet. med. Ass. 98, 288.

Green, R. G., Evans, C. A., Carlson, B. A. and Swale, F. S. (1942). J. Amer. vet. med. Ass. 100, 394.

vor. 1,1944$]$ 
Greig, J. R., Dryerre, H., Godden, W., Crichton, A. and Ogg, W. G. (1933). Vet. J. 89, 99.

Hart, G. H. and Guilbert, H. R. (1933). Bull. Calif. agric. Exp. Sta., no. 560.

Hart, G. H., Guilbert, H. R. and Goss, H. (1932). Bull. Calif. agric. Exp. Sta., no. 543 .

Hastings, C. C. (1942). J. Amer. vet. med. Ass. 100, 190.

Klemola, V. (1933). Biederm. Zbl. $[B]$ Tievernährung, 5, 657.

Madison, L. C., Miller, R. C. and Keith, T. B. (1939). Science, 89. 490.

Rupel, I. W., Bohstedt, G. and Hart, E. B. (1933). Res. Bull. Wis, agric. Exp. Sta., no. 115.

jchaible, P. J. and Bandemer, S. L. (1942). Poult. Sci. 21, 8.

Stewart, J. Unpublished data.

Underwood, E. J. and Filmer, J. F. (1935). Aust. vet. J. 11, 84.

\section{Discussion}

Dr. J. Yudkin (Dunn Nutritional Laboratory, Cambridge) said that, contrary to the experience of Dr. Mutch, experience in Cambridge had shown that it was possible, fairly easily, to find subjects with poor dark adaptation who improved with vitamin $A$.

Dr. I. Leitch (Rowett Research Institute, Bucksburn, Aberdeen) asked Professor Davidson whether he considered a comparison between haemoglobin levels in Edinburgh in 1942 with those in Aberdeen in 1935 justifiable as indicating a war time deterioration in Edinburgh. Might the 1935 levels in Edinburgh not have been lower than in Aberdeen?

Professor Davidson, in reply, said that the Aberdeen results agreed with those a t so many other centres that, although there was no pre-war Edinburgh survey, he thought the deductions were justified. Referring to the other papers in general he said he thought more clinical work on deficiency disease was needed.

Dr. H. M. Sinclair (Oxford Nutrition Survey, 10 Parks Road, Oxford) said it was surprising to hear Professor Davidson asking for more clinical and less laboratory work, particularly since all the results he had presented were derived from a laboratory estimation. Dr. Sydenstricker had stated that there was no endemic malnutrition in this country, basing this authoritative and very valuable opinion on clinical evidence alone. But this, except in the case of riboflavin deficiency, was a relatively coarse filter because specific structural changes appeared late in nutritional deficiency, and the early functional changes were vague and unspecific, as Dr. Sydenstricker had emphasized. Therefore, in general, laboratory methods must be used to detect the incidence of early malnutrition; these methods included blood estimation for haemoglobin, protein, phosphatase, carotene, vitamins $A, B_{1}$ and $C$, particularly in the leucocyte layer, perhaps nicotinic acid and riboflavin, and a reliable dark adaptation test combined with the therapeutic criterion.

As regards this test, it was surprising to hear Dr. Mutch state that it was unreliable and took too long. In the Oxford Nutrition Survey, Wald's (1941) method had been used on about 600 subjects; about 10 per cent. had given poor values and about half of those re-tested had improved significantly with vitamin A therapy. Steven (Dow and Steven, 1941), who previously worked with Wald, had shown the method was reliable. The American work on the production of poor dark adaptation in subjects on a diet deficient in vitamin $\mathrm{A}$ had been confirmed in Oxford. Patients 
from the Oxford Eye Hospital and Radcliffe Infirmary complaining of night blindness had been tested and, in most of the cases, the claim was confirmed objectively; and consistent results had been obtained by different workers on the same subjects. The method eliminated visual acuity and the psychological element, was fool proof and, by the use of a red fixation lamp, tested a particular area of the retina.

Reliable laboratory methods, critically applied, were an essential supplement to clinical methods in detecting early malnutrition in the population.

REFERENCES

Dow, D. J. and Steven, D. M. (1941). J. Physiol. 100, 256.

Wald, G. (1941). J. opt. Soc. Amer. 31, 235.

Dr. Mutch, in reply, said that the Aberdeen experience had been that, in general, rate of dark adaptation, as measured by the method used, did not correlate with dietary intake of vitamin $A$ with or without supplements. The process of dark adaptation was complicated. Different methods should be compared with the same subjects and subjects complaining of night blindness, without pathological changes in the eye, were in his experience few. 